\title{
Microbiota populations in supragingival plaque, subgingival plaque, and saliva habitats of adult dogs
}

Patrícia M. Oba ${ }^{1}$, Meredith Q. Carroll1', Celeste Alexander ${ }^{2}$, Helen Valentine ${ }^{3}$, Amy J. Somrak ${ }^{4}$, Stephanie C. J. Keating ${ }^{4}$, Adrianna M. Sage ${ }^{5}$ and Kelly S. Swanson ${ }^{1,2^{*}}$

\begin{abstract}
Background: Oral diseases are common in dogs, with microbiota playing a prominent role in the disease process. Oral cavity habitats harbor unique microbiota populations that have relevance to health and disease. Despite their importance, the canine oral cavity microbial habitats have been poorly studied. The objectives of this study were to (1) characterize the oral microbiota of different habitats of dogs and (2) correlate oral health scores with bacterial taxa and identify what sites may be good options for understanding the role of microbiota in oral diseases. We used next-generation sequencing to characterize the salivary (SAL), subgingival (SUB), and supragingival (SUP) microbial habitats of 26 healthy adult female Beagle dogs ( $4.0 \pm 1.2$ year old) and identify taxa associated with periodontal disease indices.
\end{abstract}

Results: Bacterial species richness was highest for SAL, moderate for SUB, and lowest for SUP samples $(p<0.001)$. Unweighted and weighted principal coordinates plots showed clustering by habitat, with SAL and SUP samples being the most different from one another. Bacteroidetes, Proteobacteria, Firmicutes, Fusobacteria, Actinobacteria, and Spirochaetes were the predominant phyla in all habitats. Paludibacter, Filifactor, Peptostreptococcus, Fusibacter, Anaerovorax, Fusobacterium, Leptotrichia, Desulfomicrobium, and TG5 were enriched in SUB samples, while Actinomyces, Corynebacterium, Leucobacter, Euzebya, Capnocytophaga, Bergeyella, Lautropia, Lampropedia, Desulfobulbus, Enhydrobacter, and Moraxella were enriched in SUP samples. Prevotella, SHD-231, Helcococcus, Treponema, and Acholeplasma were enriched in SAL samples. p-75-a5, Arcobacter, and Pasteurella were diminished in SUB samples. Porphyromonas, Peptococcus, Parvimonas, and Campylobacter were diminished in SUP samples, while Tannerella, Proteocalla, Schwartzia, and Neisseria were diminished in SAL samples. Actinomyces, Corynebacterium, Capnocytophaga, Leptotrichia, and Neisseria were associated with higher oral health scores (worsened health) in plaque samples.

\footnotetext{
* Correspondence: ksswanso@illinois.edu

${ }^{1}$ Department of Animal Sciences, University of Illinois at Urbana-Champaign, 1207 West Gregory Drive, 162 Animal Sciences Laboratory, Urbana, IL 61801, USA

2Division of Nutritional Sciences, University of Illinois at Urbana-Champaign, Urbana, IL 61801, USA

Full list of author information is available at the end of the article
}

(c) The Author(s). 2021, corrected publication 2021. Open Access This article is licensed under a Creative Commons Attribution 4.0 International License, which permits use, sharing, adaptation, distribution and reproduction in any medium or format, as long as you give appropriate credit to the original author(s) and the source, provide a link to the Creative Commons licence, and indicate if changes were made. The images or other third party material in this article are included in the article's Creative Commons licence, unless indicated otherwise in a credit line to the material. If material is not included in the article's Creative Commons licence and your intended use is not permitted by statutory regulation or exceeds the permitted use, you will need to obtain permission directly from the copyright holder. To view a copy of this licence, visit http://creativecommons.org/ licenses/by/4.0/. 


\begin{abstract}
(Continued from previous page)
Conclusions: Our results demonstrate the differences that exist among canine salivary, subgingival plaque and supragingival plaque habitats. Salivary samples do not require sedation and are easy to collect, but do not accurately represent the plaque populations that are most important to oral disease. Plaque Actinomyces, Corynebacterium, Capnocytophaga, Leptotrichia, and Neisseria were associated with higher (worse) oral health scores. Future studies analyzing samples from progressive disease stages are needed to validate these results and understand the role of bacteria in periodontal disease development.
\end{abstract}

Keywords: Canine, Oral microbiome, Periodontal disease, $16 \mathrm{~S}$ rRNA gene

\section{Background}

Periodontal diseases are very common in dogs, with 44$64 \%$ of dogs being affected by the disease [1-4]. Oral microbiota plays a prominent role in periodontal disease pathogenesis [5-8], as it develops as a result of plaque build-up on the teeth [9-13]. The calcification of the plaque forms the oral calculus, and the porous surface of the calculus provides the perfect condition for bacterial colonization and proliferation, which can lead to damage to the periodontium by causing deterioration of gingival connective tissue [14]. In healthy dogs, the gramnegative bacteria species are believed to be predominant, while gram-positive anaerobic species predominate in diseased animals [9].

The information generated by bacteriological analysis of the oral cavity is highly dependent on the location, or habitat, in the mouth as well as sampling technique [15]. In humans, bacterial communities were identified in seven different oral cavity habitats [buccal mucosa, keratinized gingiva, hard palate; saliva, tongue, subgingival (SUB), and supragingival (SUP) plaques], with toothassociated communities being distinct from the other oral habitats [16]. Although the technologies used were limited and the number of animals was low, similar studies have been performed in dogs. In one study, bacterial communities were identified in five different oral cavity habitats (SUB and SUP plaque, tongue, tonsils, and cheek mucosa) of seven Beagle dogs [17]. In that study, microbial communities colonizing the toothassociated habitats of the oral cavity were quite different from those colonizing the soft tissues. Furthermore, the microbiota populations most relevant to disease were in the SUB (below the gum line) and SUP (above the gum line) plaque biofilms [17]. In another study, 14 Labrador retrievers were used to identify the microbiota from four different niches within the canine oral cavity (SUP plaque, saliva, buccal and tongue dorsum mucosa) and reported that saliva exhibited the highest variability in microbial composition among dogs, yet the lowest bacterial diversity amongst all niches [18]. Local factors such as oxygen tension, $\mathrm{pH}$, and mucosal surfaces may impact the local microbiota and may be a reason for these differences. Bacterial communities may also differ due to the surface type, including soft tissue surfaces (buccal and tongue dorsum mucosa), hard tissue surfaces (SUP plaque), and saliva. Bacterial groups or metabolites, either on their own or in combinations (i.e., signatures), may be valuable in diagnosing and/or monitoring companion animal periodontal diseases in the future. Microbiota signatures are greatly dependent on habitat, however, so it is important to identify the individual or groups of bacteria that best serve as disease biomarkers and may be used for this purpose [18].

The sampling type is also important. For SUB biofilms, the information gathered from curette samples frequently differs from that obtained from paper-point samples. This is thought to be different because curettes collect plaque from the entire pocket, whereas the plaque adsorbed onto a paper point is derived mostly from the outer layers of the biofilm, which might contain the more pathogenic microbiota [19-21]. Additionally, paper points are less successful at collecting plaque in apical portions of a pocket than from areas near the gingival margin [22]. Furthermore, bacteria in SUB biofilms are not homogeneously distributed within the pocket, and for that reason, paper-point samples might not accurately represent the microbiota population at the base of the pocket where the disease is progressing [15].

Because a majority of microbial species cannot be cultured [15], advances in disease prevention have been limited. DNA-based methods of describing and studying microbes have many advantages, including the fact that they do not rely on culture methods, have greater precision, and are more accurate than traditional culture methods. Moreover, next-generation techniques that have greater speed and lower costs than traditional sequencing methods are now available. These methods allow the complete characterization of microbial populations, including those in the oral cavity, a niche that has been poorly studied in dogs. Most of the studies conducted in the past used culture techniques $[11,14,23]$ or checkerboard DNA-DNA hybridization [17] that analyzed a selected group of bacteria. The majority of studies also only collected samples from one site or compared the difference between SUP and SUB plaque. 
Characterization of the canine oral microbiome, including saliva and plaque habitats, using next-generation sequencing methods may not only identify the species present (phylogeny) but also highlight metabolic and biological pathways contributing to physiologic outcomes (metagenomics data). Once the oral microbiome of healthy dogs has been characterized, future clinical experiments focused on periodontal disease patients may be performed. Additionally, the use of oral swabs to evaluate the oral microbiota from dogs is a comparatively simple procedure when compared to the collection of canine dental plaque. Because it is less invasive and easy to collect, it is important to determine how well the salivary microbiota community relates to that of plaque. Similarities and/or differences among those populations will help determine whether saliva sampling can be used as a proxy for the characterization of plaque. Even though the dogs used in this study did not have severe periodontal disease, there was significant variability in regard to oral health scores. Therefore, our results will contribute to the foundation in the oral health area and provide guidance for future studies focused on periodontal disease of dogs.

\section{Results}

\section{Dental scoring and salivary $\mathrm{pH}$}

First, gingivitis, plaque, calculus and pocket scores were conducted by a board-certified veterinary dentist and salivary $\mathrm{pH}$ was measured using $\mathrm{pH}$ strips. All dental scores and salivary $\mathrm{pH}$ are presented in Table 1. The average tooth pocket depth of dogs was normal (1.6 \pm $0.4 \mathrm{~mm})$ and pocket bleeding was minor $(1.5 \pm 1.4)$, resulting in an average final pocket score of $2.8 \pm 2.9$. Dogs had extensive plaque coverage $(3.6 \pm 0.4)$ and thickness $(2.7 \pm 0.3)$, resulting in a final plaque score of $9.7 \pm 2.1$ [0 (low) to 12 (maximum)]. Dogs had moderate

Table 1 Dental scoring and salivary $\mathrm{pH}$ from healthy adult dogs $(n=26)$

\begin{tabular}{lll}
\hline Item & Mean & Std Deviation \\
\hline Pocket Depth & 1.6 & 0.41 \\
Pocket Bleeding & 1.5 & 1.44 \\
Plaque Coverage & 3.6 & 0.44 \\
Plaque Thickness & 2.7 & 0.33 \\
Calculus Coverage & 2.8 & 0.85 \\
Calculus Thickness & 2.0 & 0.58 \\
Oral Health Score & 19.6 & 7.43 \\
Plaque Score & 9.7 & 2.10 \\
Calculus Score & 6.1 & 2.95 \\
Gingivitis Score & 1.0 & 0.76 \\
Pocket Score & 2.8 & 2.94 \\
Salivary pH & 7.96 & 0.506 \\
\hline
\end{tabular}

calculus coverage $(2.8 \pm 0.8)$ and thickness $(2.0 \pm 0.6)$, resulting in a final calculus score of $6.1 \pm 3.0$ [0 (low) to 12 (maximum)]. Dogs had mild gingivitis $(1.0 \pm 0.8)$ and an overall oral health score (OHS; sum of plaque, calculus, gingivitis, and pocket scores) of $19.6 \pm 7.4$. Finally, mean salivary pH was $7.96 \pm 0.51$.

\section{Canine oral microbiome composition}

After $\mathrm{pH}$ was measured and teeth were scored, SUB plaque, SUP plaque, and saliva samples were collected for microbiota analysis so the communities of each habitat could be characterized and compared. Illumina sequencing produced a total of 3,897,739 16S rRNA amplicon sequences, with an average of 50,620 sequences per sample after quality filtering. Analyses were conducted with all samples rarified to a level of 19,981 sequences. Alpha and beta diversity indices were affected by sample type (habitat). Species richness differed among habitats, with SAL having the highest observed OTU (Fig. 1a) and Faith's phylogenetic diversity (Fig. 1b), SUB having moderate richness, and SUP having the lowest richness $(p<0.0001)$. SAL and SUB had similar Shannon index values that were higher than that of SUP (Fig. 1c, $p<0.0001$ ). Weighted (Fig. 2a) and unweighted (Fig. 2b) PCoA plots showed how the samples clustered according to oral habitat $(p<0.001)$. In both plots, the SAL and SUP clusters were nearly completely separated, with the SUB having overlap with each.

The oral microbiota measured in this study contained a diverse array of bacteria, including the detection of 13 phyla, with three phyla (Bacteriodetes, Proteobacteria, Firmicutes) accounting for more than $70 \%$ of sequences (Fig. 3). Oral habitat had a significant influence on the bacterial phyla (Fig. 3; Table 2), with SAL and SUB samples having lower Actinobacteria, GN02, and Proteobacteria relative abundances than SUP samples $(p<0.0001)$. SAL and SUB samples had higher Euryarchaeota and Fusobacteria relative abundances than SUP samples $(p<$ $0.0001)$. SUB and SUP samples had lower Chloroflexi ( $p=$ $0.0016)$ and ZB3 $(p=0.0002)$ relative abundances than SAL samples. Bacteroidetes, Spirochaetes, and Tenericutes relative abundances were highest in SAL, followed by SUB, and lowest in SUP samples $(p<0.0001)$. Firmicutes relative abundance was higher in SUB, followed by SAL, and lowest in SUP samples $(p<0.0001)$. SR1 relative abundance was higher in SAL, followed by SUP, and lowest in SUB samples $(p<0.0001)$. Synergistetes relative abundance was higher in SUB, followed by SUP, and lowest in SAL samples $(p<0.0001)$. TM7 relative abundance was higher in SAL than SUB samples $(p=0.0026)$.

The most predominant genera in SAL and SUB samples were Porphyromonas and Fusobacterium. In SUP samples, Porphyromonas, Moraxella, and Fusobacterium were predominant, making up to approximately $30 \%$ of 

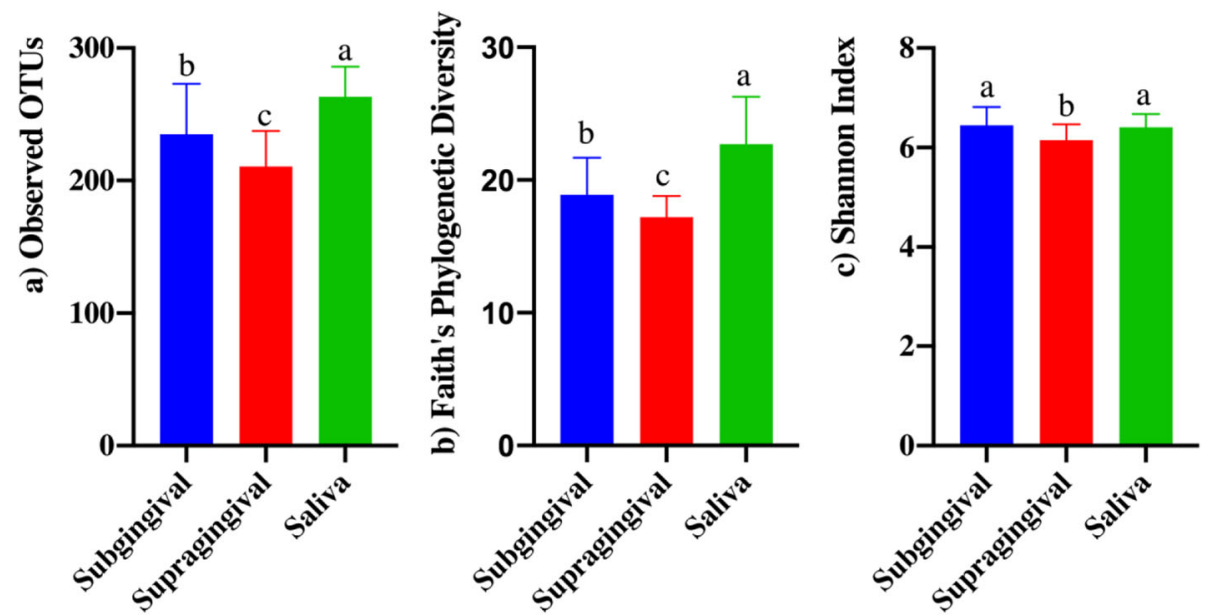

Fig. 1 Bacterial alpha diversity indices of canine salivary and plaque samples as assessed by the observed operational taxonomic units (OTU) (a), Faith's Phylogenetic Diversity (b), and Shannon Index (c). Groups with different superscripts differ $(p<0.001)$

the bacteria present (Fig. 4). Oral habitat had a significant influence on the oral bacterial genera (Fig. 4; Table 3). SAL and SUB samples had lower relative abundances of Actinomyces, Leucobacter, Lautropia, Lampropedia, Enhydrobacter, and Moraxella than SUP samples $(p<0.0001)$. SAL and SUB samples had higher relative abundances of Porphyromonas, Peptococcus, Parvimonas, and Campylobacter than SUP samples $(p<0.0001)$. SUB and SUP samples had lower relative abundances of SHD-231, Prevotella, and Helcococcus than SAL $(p<$ $0.0001)$. SUB and SUP samples had higher relative abundances of Tannerella, Proteocatella, Schwartzia, and Neisseria than SAL $(p<0.0001)$. SAL and SUP samples had higher relative abundances of Arcobacter, $p$-75-a5, and Pasteurella than SUB samples $(p=0.003)$. SAL and SUP samples had lower relative abundances of Filifactor, Fusibacter, and Leptotrichia than SUB samples $(p<$ 0.0001). Corynebacterium, Euzebya, Capnocytophaga, Bergeyella, and Desulfobulbus relative abundances were highest in SUP, followed by SUB, and lowest in SAL samples $(p<0.0001)$. Anaerovorax, Desulfomicrobium, and TG5 relative abundances were highest in SUB, followed by SUP, and lowest in SAL samples $(p<$ 0.0001). Acholeplasma and Treponema relative abundances were highest in SAL, followed by SUB, and lowest in SUP samples $(p<0.0001)$. Bacteroides and Parabacteroides relative abundances were highest in SAL samples than SUB samples $(p=0.0453)$.

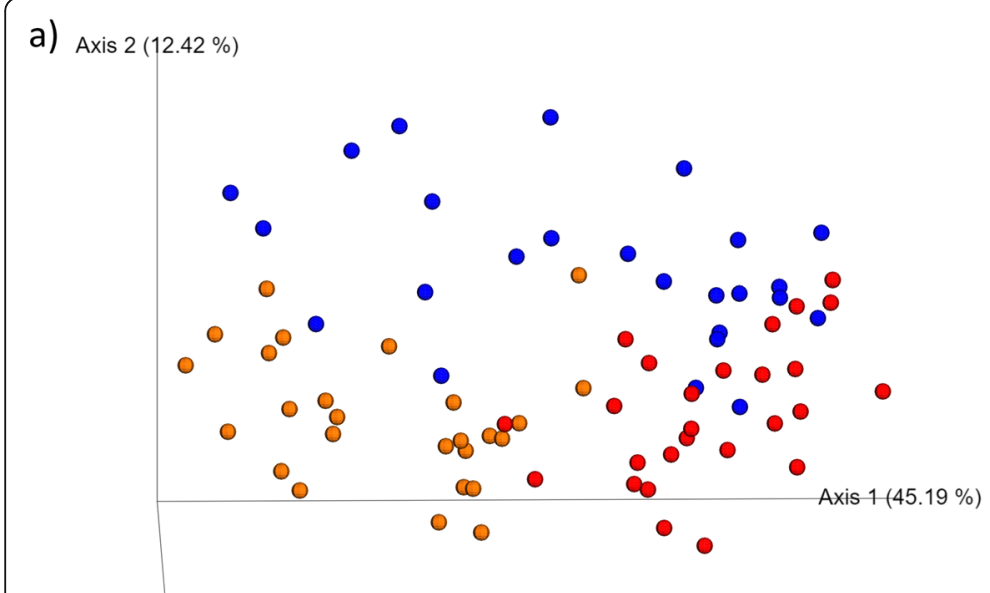

Axis $3(9.629 \%)$

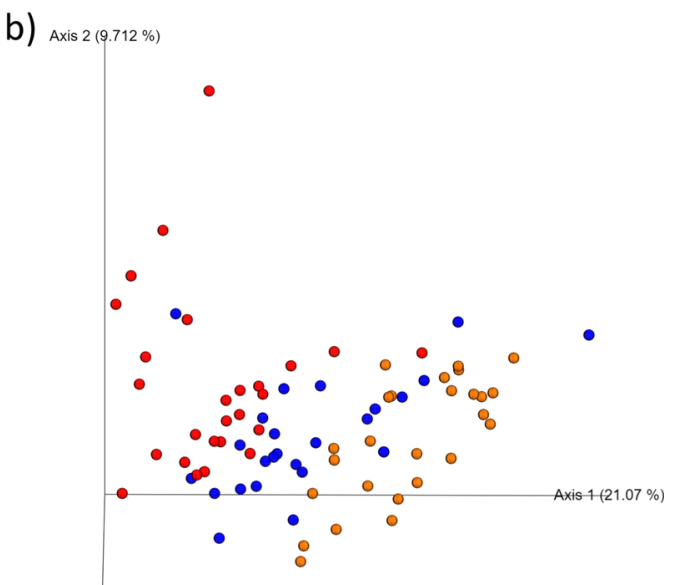

Axis $3(7.638 \%)$

Fig. 2 Principal coordinates analysis (PCOA) plots of weighted (a) and unweighted (b) UniFrac distances of oral microbial communities performed on the $97 \%$ OTU abundance matrix using QIIME 


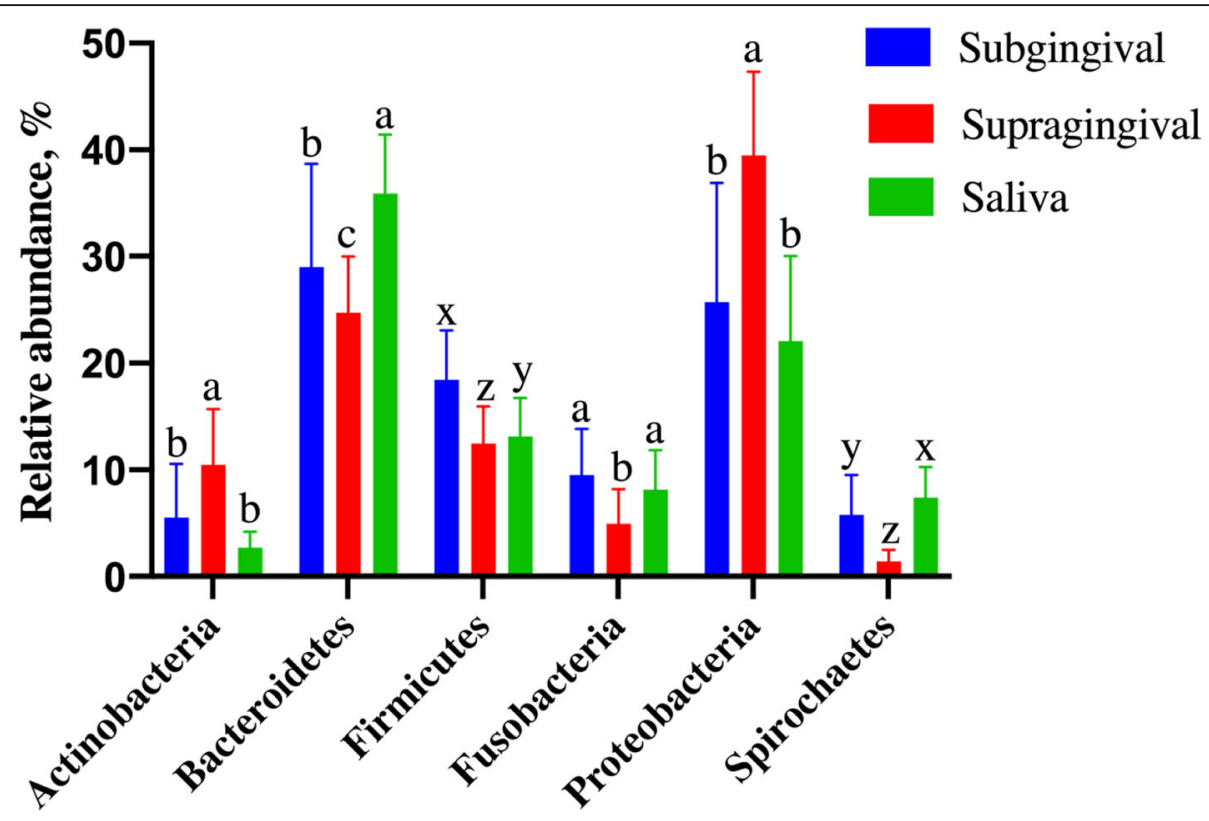

Fig. 3 Predominant oral bacterial phyla (relative abundance, \%) present in plaque (supragingival and subgingival plaque) and saliva samples of healthy adult dogs. ${ }^{\mathrm{a}-\mathrm{c}}$ Means with different superscripts within phyla differ by Tukey's test $(p<0.05) .{ }^{w-z}$ Means with different superscripts within phyla differ by Wilcoxon's test $(p<0.05)$

Table 2 Oral bacterial phyla (relative abundance, \%) present in plaque (supragingival and subgingival plaque) and saliva samples from healthy adult dogs

\begin{tabular}{|c|c|c|c|c|c|}
\hline \multirow[b]{2}{*}{ Phyla } & \multicolumn{3}{|l|}{ Source } & \multicolumn{2}{|c|}{ Statistics } \\
\hline & $\begin{array}{l}\text { Saliva } \\
(n=26)\end{array}$ & $\begin{array}{l}\text { Subgingival } \\
(n=25)\end{array}$ & $\begin{array}{l}\text { Supragingival } \\
(n=26)\end{array}$ & $\overline{\text { SEM }}$ & $P$-values \\
\hline Euryarchaeota & $0.3^{a}$ & $0.3^{\mathrm{a}}$ & $0.1^{b}$ & 0.068 & 0.0351 \\
\hline Actinobacteria & $2.7^{b}$ & $5.5^{\mathrm{b}}$ & $10.5^{\mathrm{a}}$ & 0.838 & $<0.0001$ \\
\hline Bacteroidetes & $35.9^{\mathrm{a}}$ & $29.0^{\mathrm{b}}$ & $24.7^{c}$ & 1.386 & $<0.0001$ \\
\hline Chlorobi & 1.2 & 1.4 & 1.3 & 0.147 & 0.8963 \\
\hline Chloroflexi & $0.9^{a}$ & $0.3^{b}$ & $0.4^{\mathrm{b}}$ & 0.139 & 0.0016 \\
\hline Elusimicrobia & 0.03 & 0.04 & 0.03 & 0.011 & 0.0529 \\
\hline Firmicutes & $13.2^{y}$ & $18.5^{x}$ & $12.5^{z}$ & 0.770 & $<0.0001$ \\
\hline Fusobacteria & $8.1^{\mathrm{a}}$ & $9.5^{\mathrm{a}}$ & $4.9^{b}$ & 0.746 & $<0.0001$ \\
\hline GN02 & $0.2^{b}$ & $0.3^{b}$ & $0.6^{\mathrm{a}}$ & 0.082 & $<0.0001$ \\
\hline Proteobacteria & $22.1^{\mathrm{b}}$ & $25.7^{\mathrm{b}}$ & $39.5^{\mathrm{a}}$ & 1.788 & $<0.0001$ \\
\hline SR1 & $4.2^{\mathrm{a}}$ & $2.0^{c}$ & $3.1^{b}$ & 0.338 & $<0.0001$ \\
\hline Spirochaetes & $7.4^{x}$ & $5.8^{y}$ & $1.4^{z}$ & 0.547 & $<0.0001$ \\
\hline Synergistetes & $0.3^{z}$ & $1.1^{x}$ & $0.6^{y}$ & 0.100 & $<0.0001$ \\
\hline TM7 & $0.08^{\mathrm{a}}$ & $0.04^{\mathrm{b}}$ & $0.05^{\mathrm{ab}}$ & 0.010 & 0.0026 \\
\hline Tenericutes & $3.3^{\mathrm{a}}$ & $0.5^{b}$ & $0.2^{c}$ & 0.226 & $<0.0001$ \\
\hline WPS-2 & 0.06 & 0.04 & 0.01 & 0.011 & 0.3538 \\
\hline ZB3 & $0.07^{\mathrm{a}}$ & $0.02^{\mathrm{b}}$ & $0.01^{\mathrm{b}}$ & 0.010 & 0.0002 \\
\hline
\end{tabular}

${ }^{a-c}$ Means with different superscripts within a row differ by Tukey's test $(p<0.05)$

${ }^{w-z}$ Means with different superscripts within a row differ by Wilcoxon's test $(p<0.05)$ 


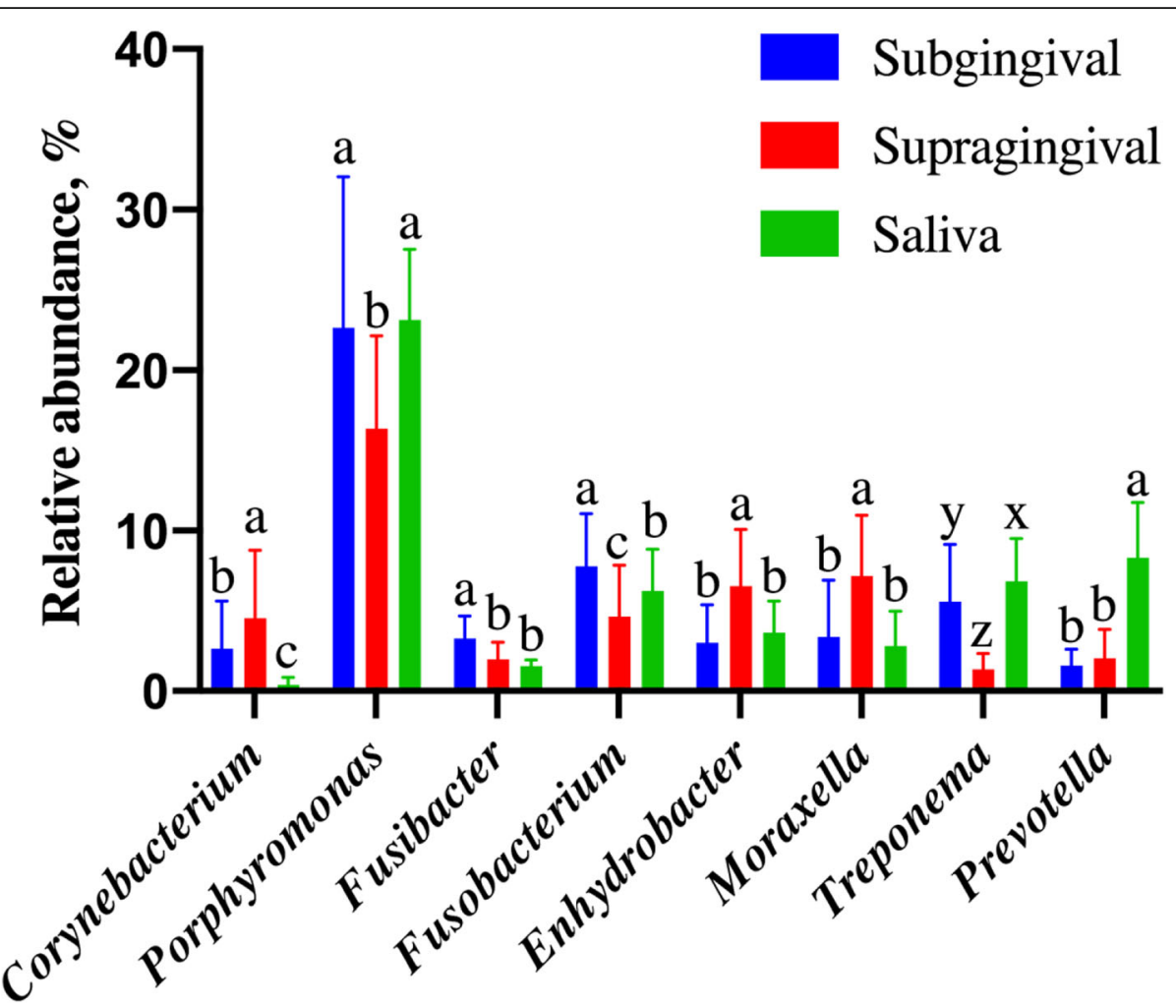

Fig. 4 Predominant oral bacterial genera (relative abundance, \%) present in plaque (supragingival and subgingival plaque) and saliva samples from healthy adult dogs. ${ }^{a-c}$ Means with different superscripts within a genera differ by Tukey's test $(p<0.05) .{ }^{w-z}$ Means with different superscripts within a genera differ by Wilcoxon's test $(p<0.05)$

Peptostreptococcus $(p<0.0001)$ and Fusobacterium $(p=$ $0.0002)$ relative abundances were highest in SUB samples, followed by SAL, and lowest in SUP samples. Oscillospira relative abundance was higher in SUP samples than SUB samples $(p=0.01)$. Propionivibrio relative abundance was higher in SUP samples than SAL samples $(p=0.005)$.

Linear discriminant analysis effect size (LEfSe) identified 4 phyla and 14 genera that were enriched in the three distinct habitats [linear discriminant analysis $(\mathrm{LDA}) \geq 3$ ]. One phylum was enriched in SUB plaque (Synergistetes) and 3 phyla were enriched in SAL (Tenericutes, Spirochaetes, and Bacteroidetes) (Fig. 5). Three genera were enriched in SUP plaque (Desulfobulbus, Leucobacter, and p_75_a5), 7 genera were enriched in SUB plaque (Desulfomicrobium, Peptooccus, Leptotrichia, Anaerovorax, TG5, Paludibacter, and Peptostreptococcus), and 4 genera were enriched in SAL (Treponema, Acholeplasma, Helcococcus, and Parvimonas) (Fig. 6).

\section{Correlation of canine oral microbiome composition and oral scores and salivary $\mathrm{pH}$}

To increase our understanding of the role that microbiota play in oral health and disease, bacterial taxa were correlated with gingivitis, plaque, calculus, and pocket scores,
OHS, and salivary $\mathrm{pH}$. Several bacterial phyla and genera were significantly correlated with $\mathrm{OHS}$ and salivary $\mathrm{pH}$ (Tables 4, 5, 6, 7, 8 and 9). Relative abundance of Actinobacteria was positively correlated with OHS (worsened health), gingivitis score, pocket score, and salivary $\mathrm{pH}$ in plaque samples (SUB and SUP). Relative abundance of Proteobacteria was positively correlated with all components of the OHS and salivary $\mathrm{pH}$ in SUP samples, and positively correlated with all oral scores except for plaque score and salivary $\mathrm{pH}$ in SUB samples. Relative abundance of Bacteroidetes was negatively correlated with all components of the OHS and salivary $\mathrm{pH}$ in SUP samples, and with all the oral scores except for plaque score and salivary pH in SUB samples. Relative abundance of Firmicutes was negatively correlated with all oral scores except for plaque score and salivary $\mathrm{pH}$ in SUB samples, with pocket and calculus score, and salivary $\mathrm{pH}$ in SUP samples, and with pocket and gingivitis score in SAL samples. Relative abundance of SR1 was negatively correlated with all components of OHS and salivary $\mathrm{pH}$ in plaque samples. Relative abundance of Tenericutes was negatively correlated with $\mathrm{OHS}$, gingivitis score, pocket score, and salivary $\mathrm{pH}$ in SUP samples, and with pocket score, gingivitis score, and salivary $\mathrm{pH}$ in SUB samples, and with OHS and salivary $\mathrm{pH}$ in SAL samples. 
Table 3 Oral bacterial genera (relative abundance, \%) present in plaque (supragingival and subgingival plaque) and saliva samples from healthy adult dogs

\begin{tabular}{|c|c|c|c|c|c|}
\hline \multirow[b]{2}{*}{ Genera } & \multicolumn{3}{|l|}{ Source } & \multicolumn{2}{|c|}{ Statistics } \\
\hline & $\begin{array}{l}\text { Saliva } \\
(n=26)\end{array}$ & $\begin{array}{l}\text { Subgingival } \\
(n=25)\end{array}$ & $\begin{array}{l}\text { Supragingival } \\
(n=26)\end{array}$ & SEM & $P$-values \\
\hline Actinomyces & $1.8^{\mathrm{b}}$ & $1.8^{\mathrm{b}}$ & $3.1^{\mathrm{a}}$ & 0.245 & $<0.0001$ \\
\hline Corynebacterium & $0.4^{c}$ & $2.6^{\mathrm{b}}$ & $4.5^{\mathrm{a}}$ & 0.590 & $<0.0001$ \\
\hline Leucobacter & $0.1^{b}$ & $0.4^{\mathrm{b}}$ & $1.6^{\mathrm{a}}$ & 0.155 & $<0.0001$ \\
\hline Euzebya & $0.3^{z}$ & $0.5^{y}$ & $0.6^{x}$ & 0.069 & 0.0008 \\
\hline Bacteroides & $1.0^{\mathrm{a}}$ & $0.7^{b}$ & $1.1^{\mathrm{ab}}$ & 0.137 & 0.0453 \\
\hline Paludibacter & $0.1^{c}$ & $0.5^{\mathrm{a}}$ & $0.3^{b}$ & 0.053 & $<0.0001$ \\
\hline Parabacteroides & $0.3^{\mathrm{a}}$ & $0.1^{b}$ & $0.2^{\mathrm{ab}}$ & 0.040 & 0.0015 \\
\hline Porphyromonas & $23.1^{\mathrm{a}}$ & $22.6^{a}$ & $16.4^{b}$ & 1.341 & $<0.0001$ \\
\hline Tannerella & $0.3^{b}$ & $0.6^{\mathrm{a}}$ & $0.5^{\mathrm{a}}$ & 0.039 & $<0.0001$ \\
\hline Prevotella & $8.3^{\mathrm{a}}$ & $1.5^{\mathrm{b}}$ & $2.1^{b}$ & 0.459 & $<0.0001$ \\
\hline Capnocytophaga & $0.2^{c}$ & $0.5^{\mathrm{b}}$ & $0.9^{\mathrm{a}}$ & 0.099 & $<0.0001$ \\
\hline Bergeyella & $0.3^{c}$ & $0.5^{b}$ & $2.0^{\mathrm{a}}$ & 0.204 & $<0.0001$ \\
\hline SHD-231 & $0.9^{\mathrm{a}}$ & $0.3^{b}$ & $0.4^{\mathrm{b}}$ & 0.139 & 0.0016 \\
\hline Streptococcus & 0.2 & 0.1 & 0.2 & 0.070 & 0.2643 \\
\hline Clostridium & 0.1 & 0.1 & 0.1 & 0.017 & 0.6114 \\
\hline Catonella & 0.4 & 0.5 & 0.5 & 0.052 & 0.7442 \\
\hline Peptococcus & $1.3^{\mathrm{a}}$ & $2.3^{\mathrm{a}}$ & $0.6^{\mathrm{b}}$ & 0.239 & $<0.0001$ \\
\hline Filifactor & $0.6^{b}$ & $1.3^{\mathrm{a}}$ & $0.7^{b}$ & 0.102 & $<0.0001$ \\
\hline Peptostreptococcus & $0.2^{b}$ & $0.4^{\mathrm{a}}$ & $0.1^{c}$ & 0.059 & $<0.0001$ \\
\hline Proteocatella & $0.1^{b}$ & $0.8^{\mathrm{a}}$ & $0.5^{\mathrm{a}}$ & 0.111 & $<0.0001$ \\
\hline Oscillospira & $0.4^{\mathrm{ab}}$ & $0.5^{\mathrm{a}}$ & $0.1^{b}$ & 0.096 & 0.0094 \\
\hline Schwartzia & $0.04^{b}$ & $0.16^{\mathrm{a}}$ & $0.06^{\mathrm{a}}$ & 0.019 & $<0.0001$ \\
\hline Fusibacter & $1.6^{\mathrm{b}}$ & $3.3^{\mathrm{a}}$ & $2.0^{\mathrm{b}}$ & 0.205 & $<0.0001$ \\
\hline Anaerovorax & $0.1^{z}$ & $0.3^{x}$ & $0.2^{y}$ & 0.033 & $<0.0001$ \\
\hline Helcococcus & $0.2^{\mathrm{a}}$ & $0.1^{b}$ & $0.1^{b}$ & 0.031 & $<0.0001$ \\
\hline Parvimonas & $0.5^{\mathrm{a}}$ & $0.5^{\mathrm{a}}$ & $0.2^{b}$ & 0.098 & $<0.0001$ \\
\hline$p-75-a 5$ & $0.2^{\mathrm{a}}$ & $0.1^{b}$ & $0.2^{\mathrm{a}}$ & 0.029 & $<0.0001$ \\
\hline Fusobacterium & $6.3^{b}$ & $7.7^{\mathrm{a}}$ & $4.6^{\mathrm{C}}$ & 0.599 & 0.0002 \\
\hline Leptotrichia & $0.04^{b}$ & $0.95^{\mathrm{a}}$ & $0.17^{\mathrm{b}}$ & 0.139 & $<0.0001$ \\
\hline Lautropia & $0.1^{b}$ & $0.2^{b}$ & $0.7^{\mathrm{a}}$ & 0.107 & $<0.0001$ \\
\hline Lampropedia & $0.5^{b}$ & $0.7^{b}$ & $2.4^{\mathrm{a}}$ & 0.201 & $<0.0001$ \\
\hline Neisseria & $0.8^{b}$ & $2.3^{\mathrm{a}}$ & $2.5^{\mathrm{a}}$ & 0.332 & $<0.0001$ \\
\hline Propionivibrio & $0.1^{b}$ & $0.1^{\mathrm{ab}}$ & $0.2^{\mathrm{a}}$ & 0.021 & 0.0049 \\
\hline Desulfobulbus & $0.1^{c}$ & $0.5^{\mathrm{b}}$ & $1.6^{\mathrm{a}}$ & 0.197 & $<0.0001$ \\
\hline Desulfomicrobium & $0.7^{2}$ & $2.5^{x}$ & $1.5^{y}$ & 0.213 & $<0.0001$ \\
\hline Desulfovibrio & 0.3 & 0.4 & 0.5 & 0.094 & 0.2526 \\
\hline Arcobacter & $2.8^{\mathrm{a}}$ & $1.2^{\mathrm{b}}$ & $2.4^{\mathrm{a}}$ & 0.560 & 0.0031 \\
\hline Campylobacter & $2.5^{\mathrm{a}}$ & $2.5^{\mathrm{a}}$ & $1.5^{b}$ & 0.186 & $<0.0001$ \\
\hline Wolinella & 0.8 & 0.7 & 0.4 & 0.130 & 0.2005 \\
\hline Pasteurella & $0.7^{\mathrm{a}}$ & $0.4^{\mathrm{b}}$ & $0.8^{\mathrm{a}}$ & 0.093 & $<0.0001$ \\
\hline Enhydrobacter & $3.7^{b}$ & $3.0^{\mathrm{b}}$ & $6.5^{\mathrm{a}}$ & 0.536 & $<0.0001$ \\
\hline Moraxella & $2.8^{\mathrm{b}}$ & $3.3^{b}$ & $7.2^{\mathrm{a}}$ & 0.637 & $<0.0001$ \\
\hline
\end{tabular}


Table 3 Oral bacterial genera (relative abundance, \%) present in plaque (supragingival and subgingival plaque) and saliva samples from healthy adult dogs (Continued)

\begin{tabular}{|c|c|c|c|c|c|}
\hline \multirow[b]{2}{*}{ Genera } & \multicolumn{3}{|l|}{ Source } & \multicolumn{2}{|c|}{ Statistics } \\
\hline & $\begin{array}{l}\text { Saliva } \\
(n=26)\end{array}$ & $\begin{array}{l}\text { Subgingival } \\
(n=25)\end{array}$ & $\begin{array}{l}\text { Supragingival } \\
(n=26)\end{array}$ & SEM & $P$-values \\
\hline Treponema & $6.9^{x}$ & $5.6^{y}$ & $1.3^{z}$ & 0.517 & $<0.0001$ \\
\hline TG5 & $0.3^{z}$ & $1.1^{x}$ & $0.6^{y}$ & 0.110 & $<0.0001$ \\
\hline Acholeplasma & $2.6^{\mathrm{a}}$ & $0.2^{b}$ & $0.1^{c}$ & 0.186 & $<0.0001$ \\
\hline
\end{tabular}

${ }^{a-c}$ Means with different superscripts within a row differ by Tukey's test $(p<0.05)$

${ }^{w-z}$ Means with different superscripts within a row differ by Wilcoxon's test $(<0.05)$

Relative abundance of Actinomyces was positively correlated with OHS, gingivitis and pocket score, and salivary $\mathrm{pH}$ in SUB samples, and with the same oral scores but not with salivary $\mathrm{pH}$ in SUP samples. Relative abundance of Corynebacterium was positively correlated with all oral scores (minus plaque score) and salivary $\mathrm{pH}$ in SUB samples, and with the same oral scores as in SUB samples (minus calculus score) and salivary pH in SUP samples. Relative abundance of Porphyromonas was negatively correlated with all oral scores and salivary $\mathrm{pH}$ in SUB samples, and with same scores (minus plaque score) and salivary $\mathrm{pH}$ in SUP samples. Relative abundance of Prevotella was negatively correlated with OHS, gingivitis and pocket score, and salivary $\mathrm{pH}$ in SUB samples, and with OHS, plaque and calculus score in SUP samples, and only with salivary $\mathrm{pH}$ in SAL samples. Relative abundance of Capnocytophaga was positively correlated with OHS, gingivitis and pocket score, and salivary $\mathrm{pH}$ in SUB samples, and with pocket score and salivary pH in SUP samples. Relative abundance of Peptococcus was negatively correlated with all oral scores (minus plaque score) and salivary $\mathrm{pH}$ in SUB samples, and with OHS and pocket score in SUP samples. Relative abundance of Filifactor was negatively correlated with all oral scores (minus plaque score) and salivary $\mathrm{pH}$ in SUB samples, and with the same oral scores as in SUB samples (minus calculus score) and salivary $\mathrm{pH}$ in SUP samples. Relative abundance of Helcococcus was negatively correlated with all oral scores (minus plaque score) and salivary pH in SUP samples, and only with salivary $\mathrm{pH}$ in SUB samples. Relative abundance of Leptotrichia was positively correlated with OHS, gingivitis and pocket score, and salivary $\mathrm{pH}$ in plaque samples. Relative abundance of Lampropedia was positively correlated with OHS, gingivitis and pocket score, and salivary $\mathrm{pH}$ in SUB samples, and with OHS, plaque, calculus, and pocket score in SUP samples. Relative abundance of Neisseria was positively correlated with OHS, gingivitis and pocket score, and salivary $\mathrm{pH}$ in SUP samples, and with pocket score in SUB samples. Relative abundance of Propionivibrio was positively correlated with gingivitis score in SUB samples, and with plaque score in SAL samples. Relative abundance of Desulfobulbus was positively correlated with all oral scores (minus plaque score) in SUP samples, and with the same score as in SUP samples (minus calculus score) in SAL and SUB samples, plus salivary $\mathrm{pH}$ in SUB samples. Relative abundance of Desulfomicrobium was positively correlated with all oral scores and salivary $\mathrm{pH}$ in SAL samples, and with OHS, calculus and gingivitis score in SUB samples. Relative abundance of Acholeplasma was negatively correlated with all oral scores (minus plaque score) and salivary $\mathrm{pH}$ in plaque samples, and with salivary $\mathrm{pH}$ in SAL samples.

\section{Discussion}

The oral microbiota of dogs in the present study was highly rich and diverse, consistent with previous studies $[9-12,24,25]$. However, it has previously been

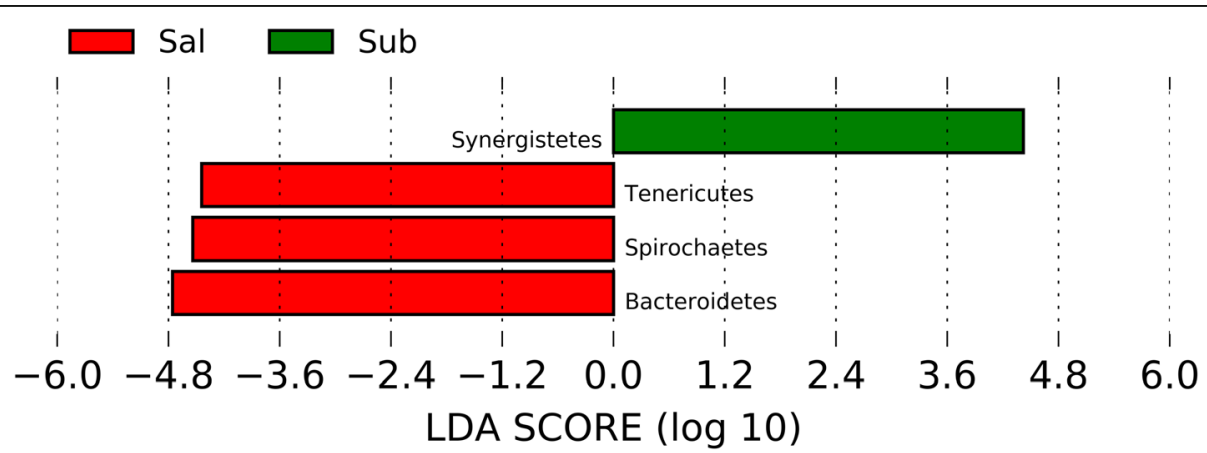

Fig. 5 LEfSe results of oral samples identified bacterial phyla enriched in salivary (SAL) and subgingival (SUB) plaque of healthy adult dogs. LDA score $\geq 3$ 


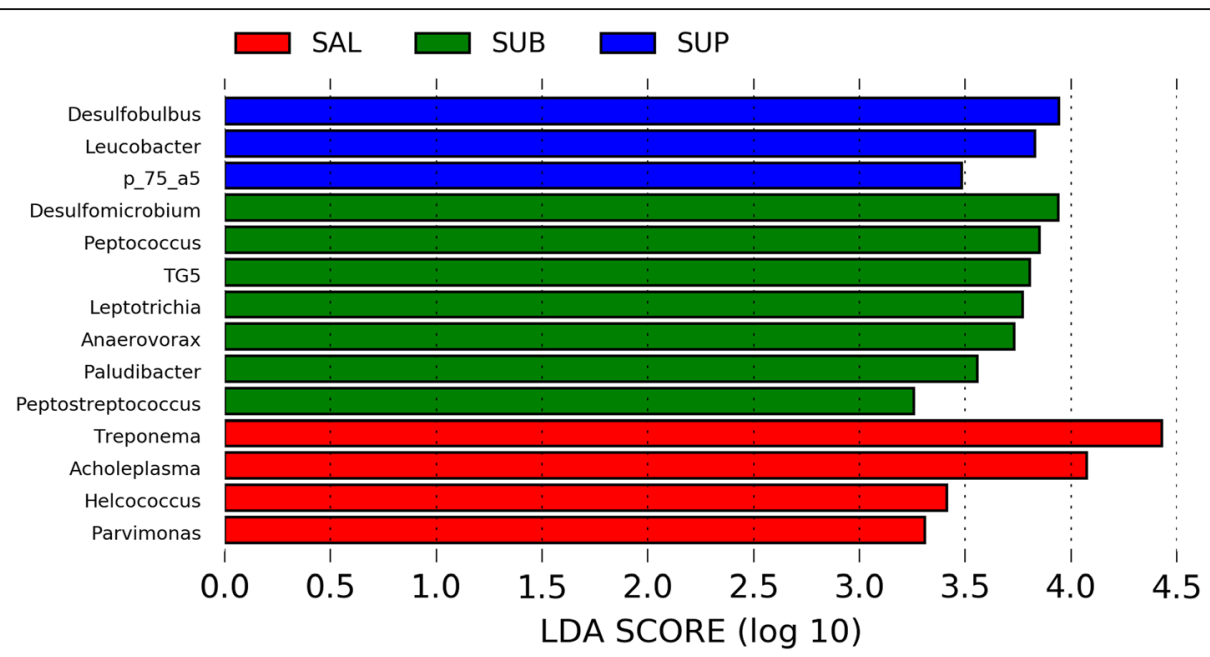

Fig. 6 LEfSe results of oral samples identified bacterial genera enriched in salivary (SAL), subgingival (SUB) plaque, and supragingival (SUP) plaque of healthy adult dogs. LDA score $\geq 3$

described that the Shannon diversity index was significantly larger for SUP and significantly smaller for SAL samples compared to all other niches [18]. In contrast to earlier findings in dogs, however, in the present study, SAL and SUB had similar Shannon index values that were higher than that of SUP. The lower diversity index value observed in the previous study for the canine saliva population may be due to the fact that the saliva was stimulated before collection, thus diluting the salivary microbiota. In the present study, the saliva was not stimulated, and therefore the samples in the present study were not diluted. Similar to the present study, in humans, studies focusing on multiple oral habitats described diversity parameters to be highest for both SUP and SAL samples $[16,26-28]$.
Davis et al. [9] reported that SUB samples from dogs of varying oral health statuses (72 with healthy gingiva; 77 with gingivitis; 74 with mild periodontitis) were colonized largely by Firmicutes, Bacteroidetes, Proteobacteria, Actinobacteria, Fusobacteria, and Spirochaetes regardless of disease stage. Additionally, in the healthy cohort, Proteobacteria and Bacteroidetes were the most abundant phyla; Porphyromonas, Moraxella, and Bergeyella were the most abundant genera in all dogs, and particularly higher in healthy animals [9]. In another study evaluating a composite oral sample of healthy dogs $(n=6)$, whereby samples were collected by brushing the gums, tongue, teeth, and cheeks, the phyla Bacteroidetes, Proteobacteria, and Firmicutes predominated; the most commonly identified genera were Porphyromonas,

Table 4 Correlation coefficients ( $r$ ) between oral health scores, plaque scores, calculus scores, gingivitis scores, pocket scores, pH, and bacterial phyla in subgingival samples $(n=25)^{1}$

\begin{tabular}{|c|c|c|c|c|c|c|c|c|c|c|c|c|}
\hline \multirow[t]{2}{*}{ Phyla } & \multicolumn{2}{|c|}{ Salivary $\mathrm{pH}$} & \multicolumn{2}{|c|}{ Pocket Score } & \multicolumn{2}{|c|}{ Gingivitis Score } & \multicolumn{2}{|c|}{ Calculus Score } & \multicolumn{2}{|c|}{ Plaque Score } & \multicolumn{2}{|c|}{ Oral Health Score } \\
\hline & $r$ & $p$ & $r$ & $\mathrm{p}$ & $r$ & $p$ & $r$ & $\mathrm{p}$ & $r$ & $p$ & $r$ & $p$ \\
\hline Actinobacteria & $\underline{0.60}$ & 0.0017 & $\underline{0.78}$ & $<0.0001$ & $\underline{0.70}$ & $<0.0001$ & 0.37 & 0.0666 & 0.33 & 0.1129 & $\underline{0.63}$ & 0.0008 \\
\hline Bacteroidetes & $\underline{-0.67}$ & 0.0002 & $\underline{-0.82}$ & $<0.0001$ & $\underline{-0.78}$ & $<0.0001$ & $\underline{-0.51}$ & 0.0100 & -0.39 & 0.0552 & $\underline{-0.72}$ & $<0.0001$ \\
\hline Chlorobi & -0.08 & 0.7181 & -0.47 & 0.0183 & -0.47 & 0.0181 & -0.22 & 0.2806 & -0.24 & 0.239 & -0.40 & 0.0503 \\
\hline Firmicutes & $\underline{-0.69}$ & 0.0001 & $\underline{-0.85}$ & $<0.0001$ & $\underline{-0.81}$ & $<0.0001$ & $\underline{-0.54}$ & 0.0050 & -0.37 & 0.0688 & $\underline{-0.75}$ & $<0.0001$ \\
\hline Fusobacteria & 0.28 & 0.1692 & 0.47 & 0.0181 & $\underline{0.58}$ & 0.0025 & 0.27 & 0.1943 & 0.20 & 0.3467 & 0.41 & 0.0413 \\
\hline GN02 & 0.22 & 0.2835 & 0.50 & 0.0118 & 0.32 & 0.1230 & 0.19 & 0.3642 & 0.35 & 0.0879 & 0.41 & 0.0437 \\
\hline Proteobacteria & $\underline{0.69}$ & 0.0001 & $\underline{0.86}$ & $<0.0001$ & $\underline{0.81}$ & $<0.0001$ & $\underline{0.54}$ & 0.0054 & 0.34 & 0.0928 & $\underline{0.74}$ & $<0.0001$ \\
\hline SR1 & -0.40 & 0.0477 & -0.47 & 0.0191 & $\underline{-0.61}$ & 0.0013 & $\underline{-0.66}$ & 0.0003 & -0.47 & 0.0174 & $\underline{-0.65}$ & 0.0005 \\
\hline Spirochaetes & -0.39 & 0.0569 & $\underline{-0.61}$ & 0.0011 & $\underline{-0.58}$ & 0.0024 & -0.16 & 0.4534 & -0.04 & 0.8574 & -0.38 & 0.0613 \\
\hline Synergistetes & -0.17 & 0.4062 & -0.45 & 0.0249 & -0.39 & 0.0571 & -0.13 & 0.539 & -0.09 & 0.6829 & -0.30 & 0.1512 \\
\hline Tenericutes & -0.60 & 0.0016 & -0.71 & $<0.0001$ & -0.64 & 0.0006 & -0.39 & 0.0552 & -0.17 & 0.4034 & -0.55 & 0.0040 \\
\hline
\end{tabular}

${ }^{1}$ Bold correlation coefficients $(r)$ with $p<0.05$, and underlined correlation coefficients $(r)$ with $r>0.5$ (strong correlation) 
Table 5 Correlation coefficients ( $r$ ) between oral health scores, plaque scores, calculus scores, gingivitis scores, pocket scores, pH, and bacterial phyla in supragingival samples $(n=26)^{1}$

\begin{tabular}{|c|c|c|c|c|c|c|c|c|c|c|c|c|}
\hline \multirow[t]{2}{*}{ Phyla } & \multicolumn{2}{|c|}{ Salivary $\mathrm{pH}$} & \multicolumn{2}{|c|}{ Pocket Score } & \multicolumn{2}{|c|}{ Gingivitis Score } & \multicolumn{2}{|c|}{ Calculus Score } & \multicolumn{2}{|c|}{ Plaque Score } & \multicolumn{2}{|c|}{ Oral Health Score } \\
\hline & $r$ & $\mathrm{p}$ & $r$ & $p$ & $r$ & $\mathrm{p}$ & $r$ & $p$ & $r$ & $p$ & $r$ & $p$ \\
\hline Actinobacteria & $\underline{0.52}$ & 0.007 & $\underline{0.53}$ & 0.0059 & 0.47 & 0.0143 & 0.37 & 0.0654 & 0.20 & 0.3319 & 0.46 & 0.0188 \\
\hline Bacteroidetes & $\underline{-0.70}$ & $<0.0001$ & $\underline{-0.83}$ & $<0.0001$ & $\underline{-0.74}$ & $<0.0001$ & $\underline{-0.62}$ & 0.0008 & -0.40 & 0.0411 & $\underline{-0.76}$ & $<0.0001$ \\
\hline Firmicutes & -0.43 & 0.0296 & $\underline{-0.53}$ & 0.0051 & -0.38 & 0.0567 & -0.41 & 0.0365 & -0.37 & 0.0596 & $\underline{-0.52}$ & 0.0066 \\
\hline Proteobacteria & $\underline{0.64}$ & 0.0004 & $\underline{0.76}$ & $<0.0001$ & $\underline{0.64}$ & 0.0004 & $\underline{0.57}$ & 0.0025 & 0.46 & 0.0187 & $\underline{0.72}$ & $<0.0001$ \\
\hline SR1 & $\underline{-0.51}$ & 0.008 & $\underline{-0.60}$ & 0.0012 & $\underline{-0.63}$ & 0.0005 & -0.43 & 0.0265 & -0.46 & 0.0178 & $\underline{-0.60}$ & 0.0011 \\
\hline Tenericutes & -0.64 & 0.0005 & $\underline{-0.60}$ & 0.0012 & $\underline{-0.56}$ & 0.0029 & -0.37 & 0.0654 & -0.21 & 0.2933 & -0.50 & 0.0092 \\
\hline
\end{tabular}

${ }^{1}$ Bold correlation coefficients $(r)$ with $p<0.05$, and underlined correlation coefficients $(r)$ with $r>0.5$ (strong correlation)

Fusobacterium, Capnocytophaga, Derxia, and Moraxella [25]. Additionally, in a healthy cohort (14 dogs), SUP samples were collected using plastic microbiological loops, buccal and tongue dorsum mucosa were collected using a CytoSoft cytology brush, and stimulated whole mouth saliva was collected using cotton wool swabs. In that study, Proteobacteria, Firmicutes, and Bacteroidetes were the most abundant phyla across all niches, although the ranking of these varied among niche [18]. Similarly, in the present study, Bacteroidetes, Proteobacteria, and Firmicutes were the predominant phyla in the SUB and SAL samples. Porphyromonas was the most abundant genus, followed by Fusobacterium, Treponema, Enhydrobacter, and Moraxella. However, Capnocytophaga and Bergeyella had a low abundance. In SUP samples, Proteobacteria, Bacteroidetes, and Firmicutes were the predominant phyla, with Porphyromonas, Moraxella, Enhydrobacter, Fusobacterium, Corynebacterium, and Actinomyces being the predominant genera. The high variability of the oral microbiota among studies may be due to differences between animals, facilities (water, food, products used for cleaning), dental prophylaxis, type of swabs, extraction protocols, and/or the amplified $16 \mathrm{~S}$ rRNA gene hypervariable region used in the microbiota analysis. Differences may also be due to interactions between the saliva, nutrient sources, host cell type, immunological factors, and exogenous factors such as oxygen availability and oral intake $[9,16]$.
In the present study, the microbiota populations were quite different among oral habitats (SAL, SUB, and SUP). The variation between SUP and SAL is consistent with data from a previous canine study whereby microbiota of SUP and oral swabs were shown to be distinct [24]. These data are also similar to data from a human study that demonstrated that the buccal mucosa, gingivae, and hard palate microbiota populations were similar to one another and different than the populations present in saliva, tongue, tonsils and throat, and SUP and SUB that were similar to one another [16]. The distinct microbiota communities of these microenvironments within the oral cavity are likely due to the differences in oxygen tension, $\mathrm{pH}$, and mucosal surface characteristics $[29,30]$.

In a previous study of 30 healthy adult Beagle dogs, SUP plaque and swabs from gums, tongue, and cheeks were sampled, reporting that Firmicutes and Spirochaetes were predominant in the plaque environment, and Proteobacteria and Firmicutes were predominant in the oral swabs [24]. Similar data were reported in the present study, with the microbiota of SAL having lower Firmicutes than the tooth plaque sites. In contrast to the previous dog study [24] where the relative abundance of Actinobacteria was higher in SUP compared to an oral swab, the relative abundance of Actinobacteria was higher in SAL compared to tooth plaque site samples (SUB and SUP) in the present study. In a previous dog

Table 6 Correlation coefficients ( $r$ ) between oral health scores, plaque scores, calculus scores, gingivitis scores, pocket scores, pH, and bacterial phyla in saliva samples $(n=26)^{1}$

\begin{tabular}{|c|c|c|c|c|c|c|c|c|c|c|c|c|}
\hline \multirow[t]{2}{*}{ Phyla } & \multicolumn{2}{|c|}{ Salivary $\mathrm{pH}$} & \multicolumn{2}{|c|}{ Pocket Score } & \multicolumn{2}{|c|}{ Gingivitis Score } & \multicolumn{2}{|c|}{ Calculus Score } & \multicolumn{2}{|c|}{ Plaque Score } & \multicolumn{2}{|c|}{ Oral Health Score } \\
\hline & $r$ & $p$ & $r$ & $p$ & $r$ & $p$ & $r$ & $\mathbf{p}$ & $r$ & $\mathbf{p}$ & $r$ & $p$ \\
\hline Euryarchaeota & 0.42 & 0.0349 & 0.42 & 0.0321 & 0.45 & 0.0206 & 0.32 & 0.1168 & 0.27 & 0.1769 & 0.42 & 0.035 \\
\hline Bacteroidetes & -0.47 & 0.0156 & -0.35 & 0.0799 & -0.31 & 0.1265 & -0.11 & 0.6035 & 0.11 & 0.5966 & -0.18 & 0.3751 \\
\hline Chloroflexi & 0.46 & 0.0175 & $\underline{0.58}$ & 0.0017 & $\underline{0.58}$ & 0.0017 & 0.50 & 0.0089 & 0.41 & 0.0377 & $\underline{0.61}$ & 0.0010 \\
\hline Firmicutes & -0.33 & 0.0971 & -0.47 & 0.0163 & -0.44 & 0.0252 & -0.13 & 0.5307 & -0.20 & 0.3275 & -0.34 & 0.0924 \\
\hline Synergistetes & $\underline{0.60}$ & 0.0013 & $\underline{0.73}$ & $<0.0001$ & $\underline{0.67}$ & 0.0002 & $\underline{0.51}$ & 0.0076 & 0.46 & 0.018 & $\underline{0.69}$ & $<0.0001$ \\
\hline Tenericutes & -0.42 & 0.0315 & -0.36 & 0.0681 & -0.30 & 0.143 & -0.38 & 0.0522 & -0.27 & 0.183 & -0.40 & 0.0413 \\
\hline
\end{tabular}

${ }^{1}$ Bold correlation coefficients $(r)$ with $p<0.05$, and underlined correlation coefficients ( $r$ ) with $-r>0.5$ (strong correlation) 
Table 7 Correlation coefficients ( $r$ ) between oral health scores, plaque scores, calculus scores, gingivitis scores, pocket scores, pH and bacteria genera in subgingival samples ${ }^{1}$

\begin{tabular}{|c|c|c|c|c|c|c|c|c|c|c|c|c|}
\hline \multirow[t]{2}{*}{ Genera } & \multicolumn{2}{|c|}{ Salivary $\mathrm{pH}$} & \multicolumn{2}{|c|}{ Pocket Score } & \multicolumn{2}{|c|}{ Gingivitis Score } & \multicolumn{2}{|c|}{ Calculus Score } & \multicolumn{2}{|c|}{ Plaque Score } & \multicolumn{2}{|c|}{ Oral Health Score } \\
\hline & $r$ & $p$ & $r$ & $p$ & $r$ & $p$ & $r$ & $p$ & $r$ & $p$ & $r$ & $p$ \\
\hline Actinomyces & 0.44 & 0.0294 & $\underline{0.68}$ & 0.0002 & $\underline{0.61}$ & 0.0011 & 0.29 & 0.1531 & 0.31 & 0.1365 & $\underline{0.54}$ & 0.0050 \\
\hline Corynebacterium & $\underline{0.62}$ & 0.0009 & $\underline{0.78}$ & $<0.0001$ & $\underline{0.70}$ & $<0.0001$ & 0.40 & 0.0480 & 0.32 & 0.1235 & $\underline{0.63}$ & 0.0007 \\
\hline Euzebya & 0.41 & 0.0429 & $\underline{0.63}$ & 0.0008 & 0.49 & 0.0134 & 0.16 & 0.4307 & 0.22 & 0.3003 & 0.43 & 0.0318 \\
\hline Bacteroides & -0.44 & 0.0268 & -0.35 & 0.0894 & -0.31 & 0.1292 & -0.23 & 0.2583 & 0.00 & 0.9988 & -0.26 & 0.2010 \\
\hline Parabacteroides & -0.14 & 0.5175 & -0.36 & 0.0753 & -0.41 & 0.0413 & -0.03 & 0.8750 & -0.11 & 0.6167 & -0.23 & 0.2653 \\
\hline Porphyromonas & -0.64 & 0.0006 & $\underline{-0.78}$ & $<0.0001$ & $\underline{-0.74}$ & $<0.0001$ & $\underline{-0.53}$ & 0.0070 & -0.44 & 0.0289 & $\underline{-0.72}$ & $<0.0001$ \\
\hline Tannerella & -0.15 & 0.4702 & -0.40 & 0.0492 & -0.21 & 0.3027 & 0.01 & 0.9545 & -0.20 & 0.3456 & -0.23 & 0.2610 \\
\hline Prevotella & -0.48 & 0.0152 & $\underline{-0.62}$ & 0.0009 & $\underline{-0.62}$ & 0.0009 & -0.35 & 0.0856 & -0.16 & 0.4521 & -0.50 & 0.0113 \\
\hline Capnocytophaga & 0.49 & 0.0133 & $\underline{0.63}$ & 0.0007 & $\underline{0.58}$ & 0.0022 & 0.23 & 0.2601 & 0.13 & 0.5482 & 0.44 & 0.0263 \\
\hline Peptococcus & $\underline{-0.53}$ & 0.0065 & $\underline{-0.59}$ & 0.0018 & $\underline{-0.64}$ & 0.0006 & -0.45 & 0.0250 & -0.27 & 0.1946 & $\underline{-0.56}$ & 0.0037 \\
\hline Filifactor & $\underline{-0.53}$ & 0.0069 & $\underline{-0.70}$ & 0.0001 & $\underline{-0.68}$ & 0.0002 & -0.45 & 0.0245 & -0.34 & 0.096 & $\underline{-0.63}$ & 0.0008 \\
\hline Proteocatella & $\underline{0.58}$ & 0.0024 & $\underline{0.61}$ & 0.0011 & $\underline{0.61}$ & 0.0012 & 0.26 & 0.2046 & 0.13 & 0.5251 & 0.45 & 0.0234 \\
\hline Schwartzia & -0.08 & 0.6931 & -0.36 & 0.0771 & -0.42 & 0.0366 & -0.17 & 0.4195 & -0.14 & 0.5122 & -0.29 & 0.1529 \\
\hline Fusibacter & -0.45 & 0.0226 & $\underline{-0.78}$ & $<0.0001$ & $\underline{-0.73}$ & $<0.0001$ & -0.49 & 0.0133 & $\underline{-0.58}$ & 0.0024 & $\underline{-0.75}$ & $<0.0001$ \\
\hline Helcococcus & -0.48 & 0.0153 & -0.30 & 0.1419 & -0.19 & 0.3632 & -0.32 & 0.1207 & -0.19 & 0.3593 & -0.32 & 0.1165 \\
\hline$p-75-a 5$ & 0.44 & 0.0272 & 0.39 & 0.0548 & 0.47 & 0.0174 & 0.23 & 0.2612 & -0.05 & 0.7997 & 0.28 & 0.1713 \\
\hline Fusobacterium & 0.20 & 0.3373 & 0.39 & 0.0531 & $\underline{0.54}$ & 0.0054 & 0.22 & 0.2831 & 0.14 & 0.5161 & 0.34 & 0.0955 \\
\hline Leptotrichia & $\underline{0.53}$ & 0.0062 & $\underline{0.71}$ & $<0.0001$ & $\underline{0.69}$ & 0.0001 & 0.26 & 0.2115 & 0.20 & 0.3459 & $\underline{0.52}$ & 0.0080 \\
\hline Lautropia & 0.37 & 0.0657 & 0.46 & 0.0210 & 0.50 & 0.0106 & 0.27 & 0.1991 & 0.07 & 0.7411 & 0.36 & 0.0757 \\
\hline Lampropedia & 0.40 & 0.0448 & 0.49 & 0.0132 & $\underline{0.53}$ & 0.0060 & 0.49 & 0.0131 & 0.21 & 0.3088 & $\underline{0.51}$ & 0.0099 \\
\hline Neisseria & 0.32 & 0.1198 & 0.46 & 0.0201 & 0.33 & 0.1116 & 0.07 & 0.7357 & 0.26 & 0.2025 & 0.32 & 0.1149 \\
\hline Propionivibrio & 0.23 & 0.2782 & 0.33 & 0.1033 & $\underline{0.51}$ & 0.0085 & 0.38 & 0.0617 & 0.19 & 0.3560 & 0.39 & 0.0522 \\
\hline Desulfobulbus & 0.47 & 0.0166 & 0.48 & 0.0147 & $\underline{0.53}$ & 0.0063 & 0.33 & 0.1051 & 0.15 & 0.4772 & 0.42 & 0.0352 \\
\hline Desulfomicrobium & 0.17 & 0.4212 & 0.30 & 0.1436 & 0.48 & 0.0164 & 0.50 & 0.0105 & 0.33 & 0.1103 & 0.46 & 0.0199 \\
\hline Arcobacter & 0.43 & 0.0311 & 0.30 & 0.1470 & 0.23 & 0.2630 & 0.24 & 0.2575 & 0.30 & 0.1401 & 0.32 & 0.1139 \\
\hline Pasteurella & 0.32 & 0.1233 & 0.57 & 0.0028 & 0.46 & 0.0206 & 0.26 & 0.2079 & 0.31 & 0.1302 & 0.47 & 0.0178 \\
\hline Moraxella & 0.49 & 0.0126 & $\underline{0.68}$ & 0.0002 & $\underline{0.52}$ & 0.0072 & 0.29 & 0.1623 & 0.21 & 0.3152 & 0.50 & 0.0108 \\
\hline Treponema & -0.38 & 0.0595 & $\underline{-0.61}$ & 0.0012 & $\underline{-0.58}$ & 0.0026 & -0.15 & 0.4738 & -0.04 & 0.8449 & -0.38 & 0.0635 \\
\hline TG5 & -0.18 & 0.3845 & -0.46 & 0.0214 & -0.40 & 0.0488 & -0.13 & 0.5280 & -0.09 & 0.6764 & -0.30 & 0.1409 \\
\hline Acholeplasma & $\underline{-0.66}$ & 0.0003 & $\underline{-0.69}$ & 0.0001 & -0.61 & 0.0014 & -0.46 & 0.0199 & -0.33 & 0.1120 & $\underline{-0.62}$ & 0.0011 \\
\hline
\end{tabular}

${ }^{1}$ Bold correlation coefficients ( $r$ ) with $p<0.05$, and underlined correlation coefficients ( $r$ ) with $r>0.5$ (strong correlation)

study, Treponema relative abundance was greater in SUP samples than oral swab samples [composite oral swabs flocked nylon-tipped BD Liquid Amies Elution swabs (Becton, Dickinson and Company, USA) - collected by swabbing the gums, tongue, and cheeks for 10-15 s], Actinomyces and Pasteurella relative abundances were greater in swab samples than SUP samples, and there was no difference in Porphyromonas relative abundance among habitats [24]. Contrary, in the present study, relative abundance of Actinomyces was higher in the SUP than SAL samples, relative abundance of Treponema and Porphyromonas were lower in the SUP than SAL samples, and relative abundance of Pasteurella was similar between SUP and SAL samples.

Furthermore, in a dog study whereby a checkerboard DNA-DNA hybridization of human probes was used, five intra-oral habitats (SUB, SUP, the tongue, tonsils and cheek mucosa) were evaluated in seven Beagle dogs [17]. In that study, the prevalence of 26 species were different between SUP and SUB plaque samples, with 20 of them being higher in SUB plaque [17]. SUP plaque contained higher proportions of $P$. gingivalis, $F$. periodonticum, $F$. nucleatum ss. vincentii, A. actinomycetemcomitans, Prevotella acnes and $A$. naeslundii genospecies 2-like species 
Table 8 Correlation coefficients ( $r$ ) between oral health scores, plaque scores, calculus scores, gingivitis scores, pocket scores, pH and bacteria genera in supragingival samples ${ }^{1}$

\begin{tabular}{|c|c|c|c|c|c|c|c|c|c|c|c|c|}
\hline \multirow[t]{2}{*}{ Genera } & \multicolumn{2}{|c|}{ Salivary pH } & \multicolumn{2}{|c|}{ Pocket Score } & \multicolumn{2}{|c|}{ Gingivitis Score } & \multicolumn{2}{|c|}{ Calculus Score } & \multicolumn{2}{|c|}{ Plaque Score } & \multicolumn{2}{|c|}{ Oral Health Score } \\
\hline & $r$ & $p$ & $r$ & $p$ & $r$ & $p$ & $r$ & $p$ & $r$ & $p$ & $r$ & $p$ \\
\hline Actinomyces & 0.26 & 0.2004 & $\underline{0.57}$ & 0.0024 & $\underline{0.50}$ & 0.0087 & 0.19 & 0.3400 & 0.20 & 0.3302 & 0.41 & 0.0376 \\
\hline Corynebacterium & $\underline{0.54}$ & 0.0047 & $\underline{0.52}$ & 0.0069 & 0.46 & 0.0191 & 0.32 & 0.1099 & 0.23 & 0.2614 & 0.44 & 0.0235 \\
\hline Leucobacter & -0.41 & 0.0372 & -0.50 & 0.0094 & $\underline{-0.57}$ & 0.0024 & -0.04 & 0.8286 & -0.12 & 0.5685 & -0.31 & 0.1278 \\
\hline Paludibacter & $\underline{0.57}$ & 0.0023 & $\underline{0.59}$ & 0.0015 & $\underline{0.52}$ & 0.0066 & 0.30 & 0.1309 & 0.09 & 0.6701 & 0.43 & 0.0276 \\
\hline Porphyromonas & $\underline{-0.70}$ & $<0.0001$ & $\underline{-0.75}$ & $<0.0001$ & $\underline{-0.60}$ & 0.0013 & -0.47 & 0.0164 & -0.26 & 0.1950 & -0.62 & 0.0008 \\
\hline Prevotella & -0.13 & 0.5346 & -0.30 & 0.1377 & -0.28 & 0.1699 & -0.41 & 0.0353 & -0.47 & 0.0146 & -0.45 & 0.0227 \\
\hline Capnocytophaga & 0.44 & 0.0240 & 0.45 & 0.0213 & 0.27 & 0.1886 & 0.17 & 0.4067 & 0.16 & 0.4378 & 0.32 & 0.1144 \\
\hline Clostridium & 0.29 & 0.1473 & 0.42 & 0.0329 & 0.50 & 0.0086 & 0.28 & 0.1671 & 0.18 & 0.3766 & 0.38 & 0.0561 \\
\hline Catonella & 0.02 & 0.9084 & -0.15 & 0.4692 & -0.14 & 0.4805 & -0.40 & 0.0427 & -0.38 & 0.0533 & -0.34 & 0.0883 \\
\hline Peptococcus & -0.34 & 0.0879 & -0.40 & 0.0414 & -0.29 & 0.1519 & -0.34 & 0.0877 & -0.37 & 0.0613 & -0.43 & 0.0285 \\
\hline Filifactor & $\underline{-0.65}$ & 0.0003 & $\underline{-0.69}$ & 0.0001 & $\underline{-0.57}$ & 0.0026 & -0.31 & 0.1235 & -0.16 & 0.4234 & -0.50 & 0.0096 \\
\hline Proteocatella & 0.42 & 0.0316 & 0.39 & 0.0505 & 0.45 & 0.0199 & 0.23 & 0.2664 & -0.02 & 0.9324 & 0.28 & 0.1589 \\
\hline Fusibacter & $\underline{-0.52}$ & 0.0066 & $\underline{-0.59}$ & 0.0016 & -0.48 & 0.0130 & -0.16 & 0.4217 & 0.00 & 0.9927 & -0.35 & 0.0837 \\
\hline Helcococcus & $\underline{-0.55}$ & 0.0034 & $\underline{-0.55}$ & 0.0038 & $\underline{-0.51}$ & 0.0083 & -0.47 & 0.0148 & -0.34 & 0.0941 & $\underline{-0.55}$ & 0.0036 \\
\hline$p-75-a 5$ & -0.04 & 0.8427 & -0.14 & 0.4835 & -0.14 & 0.5106 & -0.42 & 0.0309 & -0.36 & 0.0686 & -0.34 & 0.0877 \\
\hline Leptotrichia & 0.42 & 0.0341 & $\underline{0.59}$ & 0.0016 & 0.44 & 0.0239 & 0.30 & 0.1368 & 0.17 & 0.3946 & 0.45 & 0.0224 \\
\hline Lampropedia & 0.27 & 0.1818 & 0.42 & 0.0307 & 0.30 & 0.1308 & 0.47 & 0.0157 & $\underline{0.54}$ & 0.0044 & $\underline{0.54}$ & 0.0046 \\
\hline Neisseria & 0.49 & 0.0102 & $\underline{0.57}$ & 0.0023 & 0.40 & 0.0418 & 0.32 & 0.1100 & 0.32 & 0.1151 & 0.48 & 0.0123 \\
\hline Desulfobulbus & 0.38 & 0.0586 & $\underline{0.57}$ & 0.0025 & $\underline{0.64}$ & 0.0004 & 0.49 & 0.0107 & 0.35 & 0.0761 & 0.59 & 0.0017 \\
\hline Campylobacter & $\underline{-0.51}$ & 0.0083 & $\underline{-0.67}$ & 0.0002 & $\underline{-0.56}$ & 0.0030 & $\underline{-0.52}$ & 0.0061 & $\underline{-0.53}$ & 0.0050 & $\underline{-0.68}$ & 0.0001 \\
\hline Acholeplasma & -0.57 & 0.0026 & $\underline{-0.55}$ & 0.0033 & -0.51 & 0.0083 & -0.45 & 0.0205 & -0.19 & 0.3562 & -0.50 & 0.0087 \\
\hline
\end{tabular}

${ }^{1}$ Bold correlation coefficients $(r)$ with $p<0.05$, and underlined correlation coefficients ( $r$ ) with $r>0.5$ (strong correlation)

[17]. In the present study, SUP contained higher proportions of Actinomyces, Corynebacterium, Leucobacter, Capnocytophaga, Bergeyella, Oscillospira, p-75-a5, Lautropia, Lampropedia, Desulfobulbus, Arcobacter, Pasteurella, Enhydrobacter, and Moraxella. In the previous dog study, the microbial profiles of the soft habitats (i.e., cheek and tongue mucosa, tonsils) and tooth plaque sites were markedly different, with 19 of 40 species differing among sample locations [17]. P. gingivalis, T. denticola, Tannerella forsythia, S. constellatus, C. rectus and C. showae-like species were present in higher proportions on tooth plaque habitats [17]. In the present study, the relative abundances of 7 genera were different among saliva and tooth plaque habitats. Tannerella, Peptostreptococcus, Schwartzia, and Neisseria were present in higher proportions on tooth plaque sites.

Similar to the previous study, Tannerella was present in a higher proportion on tooth plaque sites. One of the reasons could be that Tannerella are capable of producing proteolytic enzymes that can degrade host periodontal tissues and compromise the host immune system. Tannerella also possesses a surface-associated putative adhesin that serves as ligands to other bacteria
(Fusobacterium), which provide this bacterial group with the ability to facilitate the development of complex communities and plaque formation [31-40]. Peptostreptococcus are capable of inducing a potent inflammatory reaction in macrophages, producing proteases that permit it to penetrate to the basement membrane, and creating a carbohydrate-mediated coaggregation with Fusobacterium and Porphyromonas [41-43], which also enable this bacterial genera to facilitate plaque development. In cats, Schwartzia was reported to be associated with gingivitis [44]. In humans, periodontal patients not only had higher relative abundances of periopathogens, but also of other taxa (Anaeroglobus, Bulleidia, Desulfobulbus, Filifactor, Mogibacterium, Phocaeicola, Schwartzia, or TM7) whose role in oral health are not well-established but may be targeted in future research [45]. In dogs, the primary colonizers of the tooth surface appear to be Neisseria and Moraxella [10, 46, 47]. Therefore, it was expected that a higher proportion of these bacterial groups would be measured in plaque habitats.

In a human study, it was suggested that various oral habitats (buccal mucosa, keratinized gingiva, hard palate, throat, palatine tonsils, tongue dorsum, SAL, SUP, SUB) 
Table 9 Correlation coefficients ( $r$ ) between oral health scores, plaque scores, calculus scores, gingivitis scores, pocket scores, pH and bacteria genera in saliva samples ${ }^{1}$

\begin{tabular}{|c|c|c|c|c|c|c|c|c|c|c|c|c|}
\hline \multirow[t]{2}{*}{ Genera } & \multicolumn{2}{|c|}{ Salivary $\mathrm{pH}$} & \multicolumn{2}{|c|}{ Pocket Score } & \multicolumn{2}{|c|}{ Gingivitis Score } & \multicolumn{2}{|c|}{ Calculus Score } & \multicolumn{2}{|c|}{ Plaque Score } & \multicolumn{2}{|c|}{ Oral Health Score } \\
\hline & $r$ & $p$ & $r$ & $p$ & $r$ & $p$ & $r$ & $p$ & $r$ & $p$ & $r$ & $p$ \\
\hline Paludibacter & 0.32 & 0.1118 & 0.45 & 0.0205 & 0.46 & 0.0183 & 0.15 & 0.4569 & 0.10 & 0.6351 & 0.31 & 0.1186 \\
\hline Parabacteroides & 0.47 & 0.0156 & 0.36 & 0.0748 & 0.26 & 0.2067 & 0.35 & 0.0763 & 0.36 & 0.074 & 0.41 & 0.0386 \\
\hline Prevotella & -0.42 & 0.0331 & -0.31 & 0.1288 & -0.23 & 0.2603 & -0.35 & 0.0767 & -0.03 & 0.8993 & -0.29 & 0.1478 \\
\hline SHD-231 & 0.46 & 0.0175 & $\underline{0.58}$ & 0.0017 & $\underline{0.58}$ & 0.0017 & 0.50 & 0.0089 & 0.41 & 0.0377 & $\underline{0.61}$ & 0.0010 \\
\hline Clostridium & 0.39 & 0.0499 & 0.50 & 0.0095 & 0.52 & 0.0066 & 0.48 & 0.0134 & 0.33 & 0.0988 & $\underline{0.53}$ & 0.0050 \\
\hline Catonella & 0.28 & 0.1699 & -0.05 & 0.8036 & -0.18 & 0.3918 & -0.33 & 0.099 & -0.41 & 0.0390 & -0.28 & 0.1589 \\
\hline Oscillospira & 0.50 & 0.0089 & $\underline{0.58}$ & 0.0021 & $\underline{0.61}$ & 0.0009 & 0.45 & 0.0203 & 0.35 & 0.0795 & $\underline{0.57}$ & 0.0024 \\
\hline Schwartzia & 0.48 & 0.0126 & 0.50 & 0.0101 & 0.40 & 0.0401 & 0.24 & 0.2321 & 0.17 & 0.4046 & 0.38 & 0.0541 \\
\hline Fusibacter & 0.32 & 0.1076 & 0.37 & 0.0664 & 0.38 & 0.0579 & 0.39 & 0.0468 & 0.34 & 0.0943 & 0.43 & 0.0267 \\
\hline Anaerovorax & $\underline{0.51}$ & 0.0083 & 0.49 & 0.0119 & 0.50 & 0.0091 & 0.22 & 0.2903 & 0.05 & 0.8204 & 0.34 & 0.0869 \\
\hline Fusobacterium & -0.21 & 0.3012 & -0.40 & 0.0415 & -0.40 & 0.0444 & -0.25 & 0.2237 & -0.27 & 0.1854 & -0.37 & 0.0601 \\
\hline Propionivibrio & -0.01 & 0.9801 & 0.19 & 0.3432 & 0.29 & 0.1577 & 0.35 & 0.078 & 0.43 & 0.0291 & 0.37 & 0.0656 \\
\hline Desulfobulbus & 0.29 & 0.1461 & 0.41 & 0.0355 & 0.41 & 0.0387 & 0.33 & 0.0974 & 0.35 & 0.0840 & 0.43 & 0.0265 \\
\hline Desulfomicrobium & $\underline{0.55}$ & 0.0036 & $\underline{0.71}$ & $<0.0001$ & $\underline{0.63}$ & 0.0005 & $\underline{0.57}$ & 0.0022 & 0.47 & 0.0166 & $\underline{0.71}$ & $<0.0001$ \\
\hline Desulfovibrio & 0.46 & 0.0171 & 0.50 & 0.0087 & 0.48 & 0.0134 & 0.47 & 0.0147 & 0.32 & 0.1064 & $\underline{0.53}$ & 0.0056 \\
\hline Pasteurella & -0.38 & 0.0587 & -0.26 & 0.1933 & -0.31 & 0.1215 & -0.39 & 0.0515 & -0.42 & 0.0317 & -0.41 & 0.0383 \\
\hline Enhydrobacter & 0.45 & 0.0206 & 0.43 & 0.0285 & 0.43 & 0.0289 & 0.26 & 0.1988 & 0.23 & 0.2497 & 0.38 & 0.0533 \\
\hline TG5 & $\underline{0.61}$ & 0.0009 & $\underline{0.75}$ & $<0.0001$ & $\underline{0.68}$ & 0.0001 & $\underline{0.51}$ & 0.0076 & 0.46 & 0.0176 & $\underline{0.70}$ & $<0.0001$ \\
\hline Acholeplasma & -0.42 & 0.0321 & -0.36 & 0.0736 & -0.28 & 0.1679 & -0.33 & 0.0988 & -0.25 & 0.2184 & -0.37 & 0.0615 \\
\hline
\end{tabular}

${ }^{1}$ Bold correlation coefficients $(r)$ with $p<0.05$, and underlined correlation coefficients $(r)$ with $r>0.5$ (strong correlation)

could be characterized and then easily sampled sites (e.g., SAL, tongue) could be used as surrogate markers for the others [16]. Similarly in animals, SAL and SUP samples are relatively easy to collect and do not require sedation for the majority of the animals. The data from the present study and that of a previous study [24], however, shows that the use of the oral salivary swabs to assess the oral plaque microbiota is not recommended because their communities are distinct from those of the plaque populations and would most likely be misleading. In a previous study, higher relative abundance of Treponema and Clostridiales in plaque, and higher relative abundance of Psychrobacter, Mannheimia, and Pasteurella in swab samples (gums, tongue, and cheeks), demonstrated that plaque microbiota harbor greater populations of anaerobic and biofilm-associated taxa [24]. Similarly in the present study, Paludibacter, Filifactor, Peptostreptococcus, Fusibacter, Anaerovorax, Fusobacterium, Leptotrichia, Desulfomicrobium, and TG5 (anaerobic bacteria) were enriched in SUB samples. Actinomyces, Corynebacterium, Leucobacter, Euzebya, Capnocytophaga, Bergeyella, Lautropia, Lampropedia, Desulfobulbus, Enhydrobacter, and Moraxella (aerobic and anaerobic bacteria) were enriched in SUP samples. Prevotella, SHD-231, Helcococcus, Treponema, and
Acholeplasma (aerobic and anaerobic bacteria) were enriched in SAL samples.

Identifying the relationships between oral microbiota and periodontal disease is extremely important to understand the disease process and how to prevent or treat it. Past studies have focused on Porphyromonas, as it is well known to be one of the most important bacteria for the development and progression of periodontal disease in humans [48-51]. In past studies with dogs, Porphyromonas was the most abundant genus, being particularly higher in healthy dogs $[9,25]$. In the present study, Porphyromonas was highly prevalent, providing strong evidence that they are part of the commensal oral microbiome. The data from the current and past studies suggest that instead of having a complete absence of pathogenic organisms in the normal microbiota, disease occurs when there is an imbalance $[52,53]$. Nevertheless, other groups of bacteria seem to be key components of periodontal disease in dogs, including Peptostreptococcus, Actinomyces, and Peptostreptococcaceae that have been shown to be the most predominant taxa in dogs with mild periodontitis, with Corynebacterium canis being more abundant in dogs with mild periodontitis and gingivitis, and Leptotrichia sp., Neisseria canis, and an uncultured Capnocytophaga sp. being associated with gingivitis [9]. 
In the present study we correlated bacterial genera and oral scores, and in SUB samples, Actinomyces, Corynebacterium, and Leptotrichia were strongly and positively correlated with higher pocket score, gingivitis score, and OHS. We also observed a strong positive correlation between Capnocytophaga and pocket and gingivitis scores. In SUP samples, a strong positive correlation between Actinomyces and pocket and gingivitis scores, and strong positive correlations between Corynebacterium, Leptotrichia, and Neisseria and pocket score were observed. Actinomyces belong to the group of bacteria that can overcome the immune barrier, pass through endothelial gaps and pores, penetrate the bloodstream. Therefore, it plays a significant role in gingivitis and the progression of periodontal diseases because they are able to cause inflammation, periapical lesion, and induce soft and hard tissue destruction [54-59]. Capnocytophaga spp. possess a trypsin-like enzyme and are considered to be periodontopathic [60]. Leptotrichia species typically colonize the oral cavity and have been reported to participate in oral disease in humans (gingivitis, necrotizing ulcerative gingivitis, adult/juvenile periodontitis, "refractory" periodontitis). L. buccalis is highly saccharolytic and produces lactic acid, a property that may implicate participation in tooth damage [61-66]. Additionally, nonplaque induced gingival lesions can result from specific bacterial pathogens such as Neisseria gonorrhea [67]. Therefore the correlation of those bacterial genera with higher gingivitis and pocket scores was expected. Even though ease of access and the lack of anesthesia would reduce the cost and complication of saliva collection, bacteria related to the development of periodontal disease and gingivitis are present in greater concentrations in oral plaque. Therefore, plaque collection is suggested. Unreliable data coming from SAL samples would likely lead to inaccurate diagnosis and monitoring of oral health, potentially delaying proper care and tooth cleaning that would worsen periodontal disease.

Limitations of the present study are that the (1) animals with severe oral disease were not included; this information would help understand differences in the microbiota community due to periodontal disease and (2) samples were only taken from one point of collection, with longitudinal samples over time providing a better description of the changes in oral microbiota during the development of oral disease.

\section{Conclusions}

The present study provided a broad characterization of the oral microbiome of healthy dogs. Because oral health scores differed across the population, the data may serve as a foundation for the study of healthy and diseased dogs in the future. Our results demonstrate the differences that exist among the salivary, subgingival plaque, and supragingival plaque samples of dogs. Salivary samples do not require sedation and are easy to collect, but do not accurately represent the populations most important to oral disease. Actinomyces, Corynebacterium, Capnocytophaga, Leptotrichia, and Neisseria were associated with higher oral health scores (worsened health) in plaque samples, which might be useful for future studies to understand the bacterial groups that are responsible for the development and progression of periodontal disease. A natural progression of this work is to analyze samples from progressive stages of periodontal disease, to validate the use of microbiota markers for disease.

\section{Methods \\ Animals}

Twenty-six adult female Beagle dogs $(4.0 \pm 1.2$ year old $)$ were used for saliva and plaque collection. Collection was done over the course of a few days, but methods were exactly the same for all. Dogs were housed individually in pens ( $1.0 \mathrm{~m}$ wide by $1.8 \mathrm{~m}$ long) in a humidity- and temperature-controlled animal facility. All dogs had free access to water and were fed a commercial dry kibble diet for several mo prior to sample collection and scoring. None of the dogs received antibiotics or probiotics for several mo before scoring and plaque sample collection. All procedures were approved by the University of Illinois Institutional Animal Care and Use Committee prior to experimentation.

\section{Anesthesia methods}

All dogs had their food withheld for at least $12 \mathrm{~h}$ prior to anesthesia, but were allowed water until $30 \mathrm{~min}$ prior to sedation. Dogs were premedicated with butorphanol $(0.3 \mathrm{mg} / \mathrm{kg})$. Twenty to $30 \mathrm{~min}$ after pre-medication, the fur over the cephalic vein was clipped, the site was aseptically prepared, and a 20-gauge intravenous catheter was placed in the cephalic vein for administration of anesthetic agents and intravenous fluids. Dogs were preoxygenated and anesthesia was induced with etomidate following either midazolam $\left(0.3 \mathrm{mg} \mathrm{kg}{ }^{-1}\right)$, lidocaine $\left(2 \mathrm{mg} \mathrm{kg}{ }^{-1}\right)$, or physiologic saline $(1 \mathrm{~mL})$ administered intravenously. Heart rate, invasive arterial blood pressure, respiratory rate, and intraocular pressure were recorded following butorphanol sedation, after coinduction administration, after etomidate administration, and following intubation. Dogs were orotracheally intubated and transferred to isoflurane to maintain anesthesia. Intravenous fluids were run at $5 \mathrm{~mL} / \mathrm{kg} / \mathrm{hr}$ throughout anesthesia and active heating with a forced air warmer was provided to maintain normothermia. Cardiovascular and respiratory function was monitored 
continuously using an anesthetic multiparameter monitor (electrocardiogram, oscillometric blood pressure, capnograph, pulse oximeter, and temperature). Supplementary anesthetic agents and cardiovascular support were administered as needed based on the decision of the attending anesthesiologist.

\section{Salivary $\mathrm{pH}$}

Salivary $\mathrm{pH}$ was measured using $\mathrm{pH}$ strips (Fisherbrand ${ }^{\mathrm{m}}$ Plastic pH Strips; $\mathrm{pH}$ range $0-14$ ) on the same day and time of dental scoring. All dogs had their food withheld for at least $12 \mathrm{~h}$ prior salivary $\mathrm{pH}$ measurements, using two strips on each side per dog (4 total). The salivary $\mathrm{pH}$ reported was the mean of the 4 strips. Saliva samples were collected where it naturally pools (in the cheek pouch and under the tongue) for $30 \mathrm{~s}$.

\section{Dental scoring}

Gingivitis, plaque, and calculus scoring were conducted by a board-certified veterinary dentist according to a modified version of previous scoring systems [68, 69]. For each measurement, the 4th premolar and 1st molar teeth on the upper (maxilla) and lower (mandible) jaw were scored. These two teeth were chosen because they are the teeth from which plaque samples for microbiota analysis were collected. Thus the dental score data would be more compatible with the sample collection site.

To assess gingivitis, a periodontal probe was placed subgingivally on the buccal side of each tooth and values were assigned via visual assessment of inflammation and bleeding upon probing $(0=$ normal gingiva: no inflammation; $1=$ very mild gingivitis: slight change in color, slight edema and no bleeding on probing; $2=$ mild gingivitis: redness, edema, glazing of surface, bleeding on probing within 30 -seconds; $3=$ moderate gingivitis: redness, edema, immediate bleeding on probing; $4=$ severe gingivitis: ulceration, spontaneous bleeding and profuse bleeding on probing). Each tooth was graded by the average of the three scores obtained per tooth. The score for each dog was the mean score for all teeth scored.

Plaque levels were evaluated using Trace Disclosing Solution (Young Dental, Earth City, MO, USA) to cover the teeth followed by a gentle rinse of water to remove the excess. The gingival and occlusal half of each tooth was scored for coverage $(0=$ no detectable plaque; $1=$ scattered plaque covering less than $24 \%$ of the buccal tooth surface; 2 = plaque covering between 25 and $49 \%$ of the buccal tooth surface; $3=$ plaque covering between 50 and $74 \%$ of the buccal tooth surface; plaque covering more than $75 \%$ of the buccal tooth surface) and thickness (1= light; 2 =moderate; 3 = heavy). The gingival and occlusal values for each tooth were averaged to obtain a tooth total score. The average plaque coverage was multiplied by the average of plaque thickness to obtain a whole mouth mean calculus score for each animal.

The disclosed plaque was removed by gentle tooth brushing and rinsing with a dental air-water syringe. The tooth was then air-dried. Calculus scores were based on visual assessment of coverage $(0=$ no detectable calculus; $1=$ scattered calculus covering less than $24 \%$ of the buccal tooth surface; $2=$ calculus covering between 25 and $49 \%$ of the buccal tooth surface; $3=$ calculus covering between 50 and $74 \%$ of the buccal tooth surface; $4=$ calculus covering more than $75 \%$ of the buccal tooth surface $)$ and thickness $(<0.5 \mathrm{~mm}=1 ; 00.5-$ $1.0 \mathrm{~mm}=2 ;>1.0 \mathrm{~mm}=3$ ) on the mesial, buccal, and distal portions of the tooth. The tooth score is the average of the scores for each of the three tooth surfaces. The average of calculus coverage was multiplied by the average of calculus thickness to obtain a whole mouth mean calculus score for each animal.

Pocket depth was based on height from bottom of pocket to gingival margin, $<2 \mathrm{~mm}=$ normal sulcus; $>2$ and $<3 \mathrm{~mm}=$ slight; $>3$ and $<5 \mathrm{~mm}=$ moderate; $>5$ $\mathrm{mm}=$ severe. Bleeding on probing was measured based on visual assessment of bleeding after insertion of a probe into the base of the sulcus or pocket $(0=$ normal appearing gingiva, no bleeding upon probing; $1=$ no color or contour changes, but bleeding upon probing; 2 = bleeding on probing, color change (reddening), no edema; 3 = bleeding on probing, color change, mild inflammatory edema; 4 =bleeding on probing, color change, severe inflammatory edema; $5=$ spontaneous bleeding on probing, color change, very severe inflammatory edema with or without ulceration). The tooth score is the average of pocket depth and bleeding on probing for each tooth. The average of pocket depth was multiplied by bleeding on probing to obtain a whole mouth mean pocket score for each animal. Sum of gingivitis score, plaque score, calculus score, and pocket score were used to calculate the OHS.

\section{Saliva and plaque sample collection}

Once scored, plaque (SUP and SUB plaque) and saliva samples were collected for microbiota analysis and the teeth surfaces were cleaned. Saliva samples were collected using two swabs (P-151; DNA Genotek, Ottawa, ON, Canada) per dog according to the manufacturer's guidelines. Saliva samples were collected where it naturally pools (in the cheek pouch and under the tongue) for $30 \mathrm{~s}$. Swabs were placed into the manufacturer's tube and shaken vigorously 10 times to thoroughly mix samples. Samples remained in the collection tubes at room temperature during the collection, and then were moved to $-20{ }^{\circ} \mathrm{C}$ until analysis. Teeth were assessed using a sterile periodontal probe on the gingival margin and sweeping along the base of the crown. SUB and SUP plaque samples 
were collected from the 4th premolar and 1st molar mandibular teeth and the 4th premolar and 1st molar maxillary teeth. Plaque samples were placed into sterile $2.0 \mathrm{ml}$ cryovials (CryoELITE ${ }^{\mathrm{mm}}$, Wheaton ${ }^{\mathrm{Tm}}$, Millville, NJ, USA) and immediately placed on dry ice until storage at $-80{ }^{\circ} \mathrm{C}$, where they were stored until analysis.

\section{Microbiota analysis}

Total DNA from saliva and plaque samples were extracted using Mo-Bio PowerSoil Kits (MO BIO Laboratories, Inc., Carlsbad, CA, USA), followed by quantification of extracted DNA using a Qubit 3.0 Fluorometer (Life Technologies, Grand Island, NY, USA). Quality of extracted DNA was assessed by electrophoresis using agarose gels (E-Gel EX Gel 1\%; Invitrogen, Carlsbad, CA). Bacterial $16 \mathrm{~S}$ rRNA gene amplicons of $252 \mathrm{bp}$ from the $\mathrm{V} 4$ region were generated using a Fluidigm Access Array (Fluidigm Corporation, South San Francisco, CA, USA) with Roche High Fidelity Fast Start Kit (Roche, Indianapolis, IN, USA). The primers 515F (5'-GTGCCAGCMGCCGCGGTAA-3') and 806R (5'-GGACTACHVGGGTWTCTAAT-3') that target the $252 \mathrm{bp}$-fragment of $\mathrm{V} 4$ region were used for amplification (primers synthesized by IDT Corporation, Coralville, IA, USA; [70]). Quality of the amplicons was assessed using a Fragment Analyzer (Advanced Analytics, Ames, IA, USA) followed by amplicon size selection using electrophoresis and a Qiagen Gel Purification Kit (Qiagen, Valencia, CA, USA). The appropriate profile and average size of purified amplicons were then confirmed using a Bioanalyzer (Agilent Technologies, Santa Clara, CA, USA). Amplicons were sequenced using the Illumina sequencing platform on a MiSeq using v3 reagents (Illumina Inc., San Diego, CA, USA) at the W. M. Keck Center for Biotechnology at the University of Illinois.

Quantitative Insights Into Microbial Ecology (QIIME 2 2018.8; [71]) was used to process the sequence data. Sequence data with quality value $\geq 20$ derived from the sequencing process were demultiplexed. Sequences were clustered into operational taxonomic units (OTU) using UCLUST [72] through an open-reference OTU picking strategy against the Greengenes 13_8 reference database [73] with a $97 \%$ similarity threshold. Singletons and OTU that had $<0.01 \%$ of the total observation were discarded. $\alpha$-diversity was estimated using observed OTU. $\beta$-diversity was calculated using weighted and unweighted UniFrac [74] distance measures and presented with principal coordinates analysis plots.

\section{Statistical analysis}

All data were analyzed using SAS (version 9.4, SAS Institute, Cary, NC) using the Mixed Models procedure with dog being considered a random effect, and habitat was considered a fixed effect. Data normality was checked using the univariate procedure and Shapiro-Wilk statistic, with log transformation being used when normal distribution was lacking. If after the logarithmic transformation of the data, the data did not reach normality, the data were analyzed using the npar1way procedure and Wilcoxon statistic. Correlation coefficients were calculated using the Pearson correlation coefficients. Data were reported as means with $p<0.05$ considered significant. Linear discriminant analysis effect size (LEfSe) [75] was used to evaluate the genetic sequences and to identify genera that were enriched at the various habitats.

\section{Abbreviations}

BOP: Bleeding on probing; OHS: Oral health score; PD: Pocket depth; SAL: Salivary; SUB: Subgingival plaque; SUP: Supragingival plaque; LEfSe: Linear discriminant analysis effect size; LDA: Linear discriminant analysis

\section{Acknowledgements}

The authors want to thank Kelly Sieja, Alissa Kruis, Amanda Luallan, and Xiaojing (Teresa) Yang for assistance in salivary and plaque sample collection.

\begin{abstract}
Authors' contributions
PMO and KSS conceived of and coordinated the study. PMO, MC, HV, AJS, SCJK, and AMS conducted the sample collection. PMO performed DNA extractions. PMO designed and coordinated the data analysis and drafted the initial version of the manuscript. PMO and CA contributed to data processing and statistical analysis. All authors contributed to the review of the manuscript before submission for publication. All authors read and approved the final manuscript.
\end{abstract}

\section{Funding}

Funding provided by USDA Hatch Grant ILLU-538-937.

Availability of data and materials

All sequence data are available at the NCBI sequence read archive (http:// www.ncbi.n/m.nih.gov/Traces/sra/) under accession number SUB8142132.

\section{Declarations}

Ethics approval and consent to participate

The animal study protocol was reviewed and approved by the Animal Care and Use Committee of the University of Illinois at Urbana-Champaign (IACUC \#18,082)

Consent for publication

Not applicable.

\section{Competing interests}

The authors declare that they have no competing interests.

\section{Author details}

${ }^{1}$ Department of Animal Sciences, University of Illinois at Urbana-Champaign, 1207 West Gregory Drive, 162 Animal Sciences Laboratory, Urbana, IL 61801, USA. ${ }^{2}$ Division of Nutritional Sciences, University of Illinois at Urbana-Champaign, Urbana, IL 61801, USA. ²Division of Animal Resources, University of Illinois at Urbana-Champaign, Urbana, IL 61801, USA. ${ }^{4}$ Department of Veterinary Clinical Medicine, College of Veterinary Medicine, University of Illinois, Urbana, IL 61801, USA. ${ }^{5}$ Department of Surgical Sciences, School of Veterinary Medicine, University of Wisconsin - Madison, 2015 Linden Dr, Madison, WI 53706, USA. 


\section{Received: 20 October 2020 Accepted: 30 April 2021}

\section{Published online: 17 May 2021}

\section{References}

1. Butković V, Šehič M, Stanin D, Šimpraga M, Capak D, Kos J. Dental diseases in dogs: a retrospective study of radiological data. Acta Vet Brno. 2001;70: 203-8.

2. Kyllar M, Witter K. Prevalence of dental disorders in pet dogs. Vet Med (Praha). 2005;50:496-505.

3. Kortegaard HE, Eriksen T, Baelum V. Periodontal disease in research beagle dogs - an epidemiological study. J Small Anim Pract. 2008;49:610-6.

4. Hamp S-E, Olsson S-E, Farsø-Madsen K, Viklands P, Fornell J. A macroscopic and radiological investigation of dental diseases of the dog. Vet Radiol. 1984;25:86-92.

5. Tatakis DN, Kumar PS. The etiology and pathogenesis of periodontitis. Dent Clin North Am. 2005:49:491-516.

6. Hennet PR, Harvey CE. Aerobes in periodontal disease in the dog: a review. J Vet Dent. 1991;8:9-11.

7. Mandel E, Machtou P, Torabinejad M. Clinical diagnosis and treatment of endodontic and periodontal lesions. Quintessence Int (Berl). 1993;24:135-9.

8. Gomes BPFA, Berber VB, Kokaras AS, Chen T, Paster BJ. Microbiomes of endodontic-periodontal lesions before and after chemomechanical preparation. J Endod. 2015;41:1975-84.

9. Davis IJ, Wallis C, Deusch O, Colyer A, Milella L, Loman N, et al. A crosssectional survey of bacterial species in plaque from client owned dogs with healthy gingiva, gingivitis. PLoS One. 2013;8:1-12.

10. Dewhirst FE, Klein EA, Thompson EC, Blanton JM, Chen T, Milella L, et al. The canine oral microbiome. PLoS One. 2012;7:e36067.

11. Elliott DR, Wilson M, Buckley CMF, Spratt DA. Cultivable oral microbiota of domestic dogs. J Clin Microbiol. 2005;43:5470-6.

12. Wallis C, Marshall M, Colyer A, O'Flynn C, Deusch O, Harris S. A longitudinal assessment of changes in bacterial community composition associated with the development of periodontal disease in dogs. Vet Microbiol. 2015;181: 271-82.

13. Holcombe LJ, Patel N, Colyer A, Deusch O, O'Flynn C, Harris S. Early canine plaque biofilms: characterization of key bacterial interactions involved in initial colonization of enamel. PLoS One. 2014;9:e113744.

14. Hardham J, Dreier K, Wong J, Sfintescu C, Evans RT. Pigmentedanaerobic bacteria associated with canine periodontitis. Vet Microbiol. 2005;106:119-28.

15. Loomer PM. Microbiological diagnostic testing in the treatment of periodontal diseases. Periodontol 2000. 2004;34:49-56.

16. Segata N, Haake S, Mannon P, Lemon KP, Waldron L, Gevers D, et al. Composition of the adult digestive tract bacterial microbiome based on seven mouth surfaces, tonsils, throat and stool samples. Genome Biol. 2012; 13:R42.

17. Rober M, Quirynen M, Haffajee AD, Schepers E, Teughels W. Intra-oral microbial profiles of beagle dogs assessed by checkerboard DNA-DNA hybridization using human probes. Vet Microbiol. 2008;127:79-88.

18. Ruparell A, Inui T, Staunton R, Wallis C, Deusch O, Holcombe $\sqcup$. The canine oral microbiome: variation in bacterial populations across different niches. BMC Microbiol. 2020:20:42.

19. Socransky SS, Haffajee AD. Dental biofilms: difficult therapeutic targets. Periodontol 2000. 2002;28:12-55.

20. Socransky SS, Haffajee AD, Cugini MA, Smith C, Kent RL. Microbial complexes in subgingival plaque. J Clin Periodontol. 1998;25:134-44.

21. Renvert S, Wikström M, Helmersson M, Dahlén G, Claffey N. Comparative study of subgingival microbiological sampling techniques. J Periodontol. 1992;63:797-801

22. Baker PJ, Butler R, Wikesjö UME. Bacterial sampling by absorbent paper points. An in vitro study. J Periodontol. 1991;62:142-6.

23. Harvey CE, Thornsberry C, Miller BR. Subgingival bacteria-comparison of culture results in dogs and cats with gingivitis. J Vet Dent. 1995;12:147-50.

24. Flancman R, Singh A, Weese JS. Evaluation of the impact of dental prophylaxis on the oral microbiota of dogs. PLoS One. 2018;13:e0199676.

25. Sturgeon A, Stull JW, Costa MC, Weese JS. Metagenomic analysis of the canine oral cavity as revealed by high-throughput pyrosequencing of the $16 S$ rRNA gene. Vet Microbiol. 2013;162:891-8.

26. Zaura E, Keijser BJ, Huse SM, Crielaard W. Defining the healthy "core microbiome" of oral microbial communities. BMC Microbiol. 2009:9:259. doi: https://doi.org/10.1186/1471-2180-9-259.
27. Yu G, Phillips S, Gail MH, Goedert JJ, Humphrys M, Ravel J, et al. Evaluation of buccal cell samples for studies of oral microbiota. Cancer Epidemiol Biomarkers Prev. 2017;26:249-53. doi:https://doi.org/10.1158/1055-9965.EPI-16-0538.

28. Huttenhower C, Gevers D, Knight R, Abubucker S, Badger JH, Chinwalla AT, et al. Structure, function and diversity of the healthy human microbiome. Nature. 2012:486:207-14.

29. Lamont RJ, Koo H, Hajishengallis G. The oral microbiota: dynamic communities and host interactions. Nat Rev Microbiol. 2018;16:745-59.

30. Hajishengallis G, Lamont RJ. Dancing with the stars: How choreographed bacterial interactions dictate nososymbiocity and give rise to keystone pathogens, accessory pathogens, and pathobionts. Trends Microbiol. 2016; 24:477-89.

31. Dzink JL, Socransky SS, Haffajee AD. The predominant cultivable microbiota of active and inactive lesions of destructive periodontal diseases. J Clin Periodontol. 1988:15:316-23.

32. Grossi SG, Genco RJ, Machtet EE, Ho AW, Koch G, Dunford R, et al. ssessment of risk for periodontal disease. II. Risk indicators for alveolar bone loss. J Periodontol. 1995;66:23-9.

33. Holt SC, Bramanti TE. Factors in virulence expression and their role in periodontal disease pathogenesis. Crit Rev Oral Biol Med. 1991;2:177-281.

34. Listgarten MA, Lai C-H, Young V. Microbial composition and pattern of antibiotic resistance in subgingival microbial samples from patients with refractory periodontitis. J Periodontol. 1993;64:155-61.

35. Sharma A, Inagaki S, Honma K, Sfintescu C, Baker PJ, Evans RT. Tannerella forsythia -induced Alveolar Bone Loss in Mice Involves Leucine-rich-repeat BspA Protein. J Dent Res. 2005;84:462-7.

36. Tanner A, Maiden MFJ, Macuch PJ, Murray LL, Kent RL. Microbiota of health, gingivitis, and initial periodontitis. J Clin Periodontol. 1998;25:85-98.

37. Tanner ACR, lzard J. Tannerella forsythia, a periodontal pathogen entering the genomic era. Periodontol 2000. 2006:42:88-113.

38. Potempa J, Pike RN. Corruption of innate immunity by bacterial proteases J Innate Immun. 2009:1:70-87.

39. Sharma A. Virulence mechanisms of Tannerella forsythia. Periodontol 2000 2010;54:106-16.

40. Sharma A, Inagaki S, Sigurdson W, Kuramitsu HK. Synergy between Tannerella forsythia and Fusobacterium nucleatum in biofilm formation. Oral Microbiol Immunol. 2005;20:39-42.

41. Yamaguchi M, Terao Y, Ogawa T, Takahashi T, Hamada S, Kawabata S. Role of Streptococcus sanguinis sortase A in bacterial colonization. Microbes Infect. 2006:8:2791-6.

42. Kumar PS, Leys EJ, Bryk JM, Martinez FJ, Moeschberger ML, Griffen AL. Changes in periodontal health status are associated with bacterial community shifts as assessed by quantitative 165 cloning and sequencing. J Clin Microbiol. 2006:44:3665-73.

43. Balaji A, Surekha V, Mahalakshmi K, Valiatthan M. Gram-positive microorganisms in periodontitis. Drug Invent Today. 2019;12:1199-203.

44. Harris S, Croft J, O'Flynn C, Deusch O, Colyer A, Allsopp J, et al. A pyrosequencing investigation of differences in the feline subgingival microbiota in health, gingivitis and mild periodontitis. PLoS One. 2015;10:122. doi:https://doi.org/10.1371/journal.pone.0136986.

45. Camelo-Castillo AJ, Mira A, Pico A, Nibali L, Henderson B, Donos N, et al. Subgingival microbiota in health compared to periodontitis and the influence of smoking. Front Microbiol. 2015;6:119.

46. Dahlén G, Charalampakis G, Abrahamsson I, Bengtsson L, Falsen E. Predominant bacterial species in subgingival plaque in dogs. J Periodontal Res. 2012:47:354-64.

47. Sanguansermsri $P$, Chairatvit K, Roytrakul S, Doungudomdacha S, Surarit R. Exploring difference in subgingival microbial communities in dog and human periodontal diseases using DGGE technique. Thai J Vet Med. 2017; 47:7-14.

48. Hajishengallis G, Liang S, Payne MA, Hashim A, Jotwani R, Eskan MA, et al. Low-abundance biofilm species orchestrates inflammatory periodontal disease through the commensal microbiota and complement. Cell Host Microbe. 2011:10:497-506.

49. Holt SC, Kesavalu L, Walker S, Genco CA. Virulence factors of Porphyromonas gingivalis. Periodontol 2000. 1999;20:168-238.

50. Lamont RJ, Jenkinson HF. Life below the gum line: Pathogenic mechanisms of Porphyromonas gingivalis. Microbiol Mol Biol Rev. 1998;62:1244-63.

51. Amano A, Nakagawa I, Kataoka K, Morisaki I, Hamada S. Distribution of Porphyromonas gingivalis strains with fimA genotypes in periodontitis patients. J Clin Microbiol. 1999;37:1426-30. 
52. Lenski RE, May RM. The evolution of virulence in parasites and pathogens: reconciliation between two competing hypotheses. J Theor Biol. 1994;169:253-65.

53. Little TJ, Shuker DM, Colegrave N, Day T, Graham AL. The coevolution of virulence: tolerance in perspective. PLoS Pathog. 2010;6:e1001006.

54. Hajishengallis $\mathrm{G}$, Lamont RJ. Beyond the red complex and into more complexity: the polymicrobial synergy and dysbiosis (PSD) model of periodontal disease etiology. Mol Oral Microbiol. 2012;27:409-19.

55. Yamasaki Y, Nomura R, Nakano K, Naka S, Matsumoto-Nakano M, Asai F, et al. Distribution of periodontopathic bacterial species in dogs and their owners. Arch Oral Biol. 2012;57:1183-8. doi:https://doi.org/10.1016/j.archora Ibio.2012.02.015

56. Faveri M, Figueiredo LC, Duarte PM, Mestnik MJ, Mayer MPA, Feres M. Microbiological profile of untreated subjects with localized aggressive periodontitis. J Clin Periodontol. 2009;36:739-49.

57. Xia T, Baumgartner J. Occurrence of Actinomyces in infections of endodontic origin. J Endod. 2003;29:549-52.

58. Sato T, Watanabe K, Kumada H, Toyama T, Tani-Ishii N, Hamada N. Peptidoglycan of Actinomyces naeslundii induces inflammatory cytokine production and stimulates osteoclastogenesis in alveolar bone resorption. Arch Oral Biol. 2012;57:1522-8.

59. Shimada E, Kataoka H, Miyazawa Y, Yamamoto M, Igarashi T. Lipoproteins of Actinomyces viscosus induce inflammatory responses through TLR2 in human gingival epithelial cells and macrophages. Microbes Infect. 2012;14: 916-21.

60. Ishihara K, Naito Y, Kato T, Takazoe I, Okuda K, Eguchi T, et al. A sensitive enzymatic method (SK-013) for detection and quantification of specific periodontopathogens. J Periodontal Res. 1992;27:81-5.

61. Eribe ERK, Olsen I. Leptotrichia species in human infections. Anaerobe. 2008; 14:131-7.

62. Könönen E, Asikainen S, Saarela M, Karjalainen J, Jousimies-Somer H. The oral gram-negative anaerobic microflora in young children: longitudinal changes from edentulous to dentate mouth. Oral Microbiol Immunol. 1994; 9:136-41.

63. Colombo AP, Haffajee AD, Dewhirst FE, Paster BJ, Smith CM, Cugini MA, et al. Clinical and microbiological features of refractory periodontitis subjects. J Clin Periodontol. 1998;25:169-80.

64. Vernelen K, Mertens I, Thomas J, Vandeven J, Verhaegen J. Verbist. L. Bacteraemia with Leptotrichia Buccalis: report of a case and review of the literature. Acta Clin Belg. 1996;51:265-70.

65. van Houte J. Role of Micro-organisms in Caries Etiology. J Dent Res. 1994;73: 672-81.

66. Hofstad T. Pathogenicity of anaerobic gram-negative rods: possible mechanisms. Clin Infect Dis. 1984;6:189-99.

67. Wiebe CB, Putnins EE. The periodontal disease classification system of the American Academy of Periodontology-an update. Journal-canadian Dent Assoc. 2000;66:594-9.

68. Gorrel C, Warrick J, Bierer TL. Effect of a new dental hygiene chew on periodontal health in dogs. J Vet Dent. 1999;16:77-81.

69. Mühlemann HR, Son S. Gingival sulcus bleeding-a leading symptom in initial gingivitis. Helv Odontol Acta. 1971:15:107-13.

70. Caporaso JG, Lauber CL, Walters WA, Berg-Lyons D, Huntley J, Fierer N, et al. Ultra-high-throughput microbial community analysis on the Illumina HiSeq and MiSeq platforms. ISME J. 2012;6:1621-4.

71. Caporaso JG, Kuczynski J, Stombaugh J, Bittinger K, Bushman FD, Costello EK, et al. QIIME allows analysis of high-throughput community sequencing data. Nat Methods. 2010;7:335-6.

72. Edgar RC. Search and clustering orders of magnitude faster than BLAST. Bioinformatics. 2010;26:2460-1.

73. DeSantis TZ, Hugenholtz P, Larsen N, Rojas M, Brodie EL, Keller K, et al. Greengenes, a Chimera-Checked 16S rRNA gene database and workbench compatible with ARB. Appl Environ Microbiol. 2006;72:5069-72.

74. Lozupone C, Knight R. UniFrac: a new phylogenetic method for comparing microbial communities. Appl Environ Microbiol. 2005;71:8228-35.

75. Segata N, lzard J, Waldron L, Gevers D, Miropolsky L, Garrett WS, et al. Metagenomic biomarker discovery and explanation. Genome Biol. 2011;12:1-18.

\section{Publisher's Note}

Springer Nature remains neutral with regard to jurisdictional claims in published maps and institutional affiliations.

\section{Ready to submit your research? Choose BMC and benefit from:}

- fast, convenient online submission

- thorough peer review by experienced researchers in your field

- rapid publication on acceptance

- support for research data, including large and complex data types

- gold Open Access which fosters wider collaboration and increased citations

- maximum visibility for your research: over $100 \mathrm{M}$ website views per year

At BMC, research is always in progress.

Learn more biomedcentral.com/submissions 